\title{
Mouse Metanephric Mesenchymal Cell-Derived Angioblasts Undergo Vasculogenesis in Three-Dimensional Culture
}

Mandakini Patel, * Chakradhar Velagapudi, ${ }^{*}$ Hannah Burns, ${ }^{\dagger}$ Robert Doss, ${ }^{\dagger}$ Myung-Ja Lee, ${ }^{\dagger}$ Meenalakshmi M. Mariappan, Brent Wagner, ${ }^{*}$ Mazen Arar, ${ }^{\S}$ Veronique L. Barnes, ${ }^{\dagger}$ Hanna E. Abboud, ${ }^{* \ddagger}$ and Jeffrey L. Barnes ${ }^{* \dagger}$

From the Department of Medicine, ${ }^{*}$ Division of Nephrology, The Medical Research Service, ${ }^{\ddagger}$ Audie Murphy Memorial Veterans Administration Hospital, South Texas Veterans Health Care System, and the Department of Pediatrics, ${ }^{\S}$ The University of Texas Health Science Center, San Antonio; and Probetex, Inc., ${ }^{\dagger}$ San Antonio, Texas

Accepted for publication October 30, 2017.

Address correspondence to Jeffrey L. Barnes, Ph.D., Probetex, Inc., 7418 John Smith Dr., Ste. A, San Antonio, TX. E-mail: jlbarnes@probetex.com.
In vitro models for the investigation of renal vascular development are limited. We previously showed that isolated metanephric mesenchymal (MM) and ureteric bud (UB) cells grown in three-dimensional (3D) matrices formed organoids that consisted of primitive vascular structures surrounding a polarized epithelium. Here, we examined the potential of two principal effectors of vasculogenesis, vascular endothelial growth factor A (VEGF-A), and platelet-derived growth factor B chain (PDGF-BB), to stimulate MM cell differentiation. The results showed that MM cells possess angioblast characteristics by expressing phenotypic markers for endothelial and mesenchymal cells. UB cells synthesize VEGF-A and PDGF-BB proteins and RNA, whereas the MM cells express the respective cognate receptors, supporting their role in directional induction of vasculogenesis. VEGF-A stimulated proliferation of MM cells in monolayer and in 3D sponges but did not affect MM cell migration, organization, or vasculogenesis. However, PDGF-BB stimulated MM cell proliferation, migration, and vasculogenesis in monolayer and organization of the cells into primitive capillary-like assemblies in $3 \mathrm{D}$ sea sponge scaffolds in vitro. A role for PDGF-BB in vasculogenesis in the $3 D$ MM/UB co-culture system was validated by direct interference with PDGF-BB or PDGF receptor- $\beta$ cell interactions to implicate PDGF-BB as a primary effector of MM cell vasculogenesis. Thus, MM cells resemble early renal angioblasts that may provide an ideal platform for the investigation of renal vasculogenesis in vitro. (Am J Pathol 2018, 188: 768-784; https://doi.org/10.1016/j.ajpath.2017.10.022)
During kidney development, the metanephric mesenchyme (MM) induces branching morphogenesis of the ureteric bud (UB) eventually giving rise to the collecting duct (CD) system, renal pelvis, and ureter. ${ }^{1}$ In turn, the mesenchyme aggregates and becomes cap mesenchyme around the advancing tips of the UB and is induced to differentiate into visceral epithelial cells of the glomerulus, proximal tubule, loop of Henle, and distal tubule. ${ }^{1,2}$ The renal vasculature is believed to be derived from two cell sources in the metanephric mesenchyme. Angioblasts bearing vascular endothelial growth factor (VEGF) receptor 2 (Flk-1) are considered to be the source of endothelial cells, ${ }^{3,4}$ and stromal mesenchymal cells are destined to become mesangial cells of the emerging glomerulus as well as pericytes and mural cells that form peritubular capillary and vascular network throughout the developing kidney. ${ }^{4-8}$ Evidence for a common vascular precursor has been afforded by the observation that

Supported by NIH/National Institute of Diabetes and Digestive and Kidney Disease Small Business Technology Transfer grant R42 DK077436 (J.L.B.), Small Business Innovation Research (SBIR) grants R44 DK061834 (V.L.B.), and R43 GM1 10837 (V.L.B.), and NIH grant R01 DK-102085 (B.W.), and the Veterans Administration Merit Review Program (J.L.B. and B.W.).

M.P. and C.V. contributed equally to this work.

This article is dedicated to the memory of Dr. Hanna E. Abboud, M.D., a great friend and investigator instrumental in the isolation of the cell lines used in this article.

Disclosures: M.A. and V.L.B. received patent royalties from Probetex, Inc. V.L.B. is owner and president of Probetex, Inc. J.L.B. received consulting fees from Probetex, Inc. H.B., R.D., M.-J.L., and M.M.M. are employees of Probetex, Inc. 
Flk- $1^{+}$-sorted stem cells have the capacity to differentiate into endothelial or mural cells in response to VEGFA or platelet-derived growth factor B chain (PDGF-BB), respectively. ${ }^{9}$ In addition, a recent report indicates that stromal mesenchymal cells in the kidney and lung may differentiate into both mural/pericyte and endothelial cells, ${ }^{10}$ pointing toward a common angioblast progenitor in the development of the vascular system. Indeed, previous studies in our laboratory have indicated that precursor cells in the cleft of the developing glomerulus express both mesenchymal and endothelial cell markers, suggesting a common angioblast progenitor for glomerular capillary development. ${ }^{8}$

We previously showed that co-culture of isolated mouse MM and UB cell lines in three-dimension (3D) culture recreated a reciprocal induction of the cells into organotypic structures. ${ }^{11} \mathrm{MM}$ cells developed into capillary-like structures that surround UB-derived epithelial cells with CD characteristics. ${ }^{11}$ These studies suggested that MM and UB cells secrete soluble substances that initiate cell tropism and migration, cell-cell contact, and induction of differentiation into specialized vascular and epithelial structures, respectively. Indeed, differentiation of UB cells may be induced to form epithelial structures when grown in 3D Matrigel matrix in the presence of MM cell-derived conditioned medium, glial-derived neurotrophic factor, hepatocyte growth factor, or fibronectin. ${ }^{11,12}$ In addition, UB cell-derived conditioned medium induced $\mathrm{MM}$ cell migration in in vitro assay, suggesting that UB cells secrete substances important in the formation of capillary structures in $3 \mathrm{D}$ co-culture. ${ }^{11}$ The identities of the UB-derived factors that induce $\mathrm{MM}$ vasculogenesis in this system have not been determined.

A number of growth factors are involved in vasculogenesis among which VEGF-A and PDGF-BB play formative roles. ${ }^{13-15}$ Both growth factors are produced by glomerular and tubular eptihelia, and their cognate receptors are present on mesenchymal/endothelial progenitor cells in the developing interstitial niche, a requirement for a directional stimulation of cell migration and differentiation during vasculogenesis. Indeed, interruption of interactions of either growth factor or receptor prevents vascular development. In this present article we describe a MM cell line that appears to resemble a common angioblast progenitor cell in that it expresses both mesenchymal and endothelial cell characteristics and differentiates into primitive capillary-like structures in vitro. We previously reported that the $\mathrm{MM}$ cells proliferate and migrate in response to PDGF-BB in two-dimensional (2D) cell culture monolayer, ${ }^{16-18}$ implicating this growth factor as a candidate for induction of MM vasculogenesis in the 3D co-culture system. A role for VEGF-A in these MM cells in monolayer or in $3 \mathrm{D}$ culture has not been explored. Here, we further characterize the vascular characteristics of our MM cell line and investigate their potential to undergo vasculogenesis in response to VEGF-A and PDGF-BB in 3D sea sponge scaffolds and in co-culture with UB cells in Matrigel implants. The results showed that PDGF-BB, but not VEGF, was responsible for MM vasculogenesis in the $3 \mathrm{D}$ co-culture systems. These studies provide an ideal 3D platform to study renal vasculogenesis in vitro.

\section{Materials and Methods}

\section{Mouse MM and UB Cell Culture}

Mouse UB and MM (CMUB-1, CMMM-1; Probetex, Inc., San Antonio, TX) and MM cells deficient of PDGF receptor (PDGFR)- $\beta$ null $(-/-)^{17,18}$ were characterized, grown, and maintained at $37^{\circ} \mathrm{C}$ in $5 \% \mathrm{CO}_{2}$ in Dulbecco's Modified Eagle's Medium (DMEM) that contained 10\% fetal bovine serum as originally described. ${ }^{11,12,17}$ The cells were grown to confluence, underwent cell dissociation with trypsin, and washed for subsequent growth in monolayer and 3D culture as described below. PDGF-BB and VEGF-A (R\&D Systems, Minneapolis, MN) were used at concentrations previously used by our laboratory or known to induce vasculogenesis in culture (Cell Proliferation).

\section{Western Blot Analysis}

MM and UB cells were examined by immunoblotting for the expression of mesenchymal and endothelial markers. In addition, MM and UB cell expression of PDGF-BB chain or VEGF-A proteins were examined by immunoblotting with the use of standard techniques as previously reported. ${ }^{11,17}$ Sources of antibodies are listed in Table 1. Signal was detected with a Syngene ChemiHR16 photo documentation system or by film radiography. Detection of glyceraldehyde-3-phosphate dehydrogenase was used as a loading control.

\section{Uptake of DiI-Ac-LDL}

Endothelial phenotype was further assessed by metabolism of acetylated low-density lipoprotein (Ac-LDL), labeled with $1,1^{\prime}$-dioctadecyl-3,3,3',3'-tetramethyl-indocarbocyanine perchlorate (DiI) (obtained from Thermo Fisher, Waltham, MA) as previously described. ${ }^{19}$ DiI-AcLDL was diluted to $10 \mu \mathrm{g} / \mathrm{mL}$ in complete growth media, added to the MM and UB cells, and incubated for 4 hours at $37^{\circ} \mathrm{C}$. The cells were washed with warm phosphate-buffered saline (PBS), lightly fixed with $10 \%$ neutral buffered formalin for 2 minutes, then mounted with immunomount. The cells were viewed and photographed with ZOE Fluorescent Cell Imager (Bio-Rad Laboratories, Hercules, CA) or Olympus (Melville, NY) AX70 research microscope and DP70 digital camera. 
Table 1 Differentiation Markers: Antibody Source, Targets, Species, and Concentrations

\begin{tabular}{|c|c|c|c|}
\hline Primary antibody & Target cell & Source & Species/concentration \\
\hline \multicolumn{4}{|l|}{ Mesenchymal markers } \\
\hline$\alpha-S M A(1 A 4)$ & Mesenchymal, pericytes & Sigma-Aldrich, St. Louis, MO & Mouse $/ 10 \mu \mathrm{g} / \mathrm{mL}$ \\
\hline PDGFR- $\beta$ (958) & Mesenchymal, pericytes & $\begin{array}{l}\text { Santa Cruz Biotechnology, } \\
\text { Santa Cruz, CA }\end{array}$ & Rabbit/10 $\mu \mathrm{g} / \mathrm{mL}$ \\
\hline Foxd1 (C-19) & $\begin{array}{l}\text { Mesenchymal, stromal, } \\
\text { endothelial }\end{array}$ & Santa Cruz Biotechnology & Goat $/ 20 \mu \mathrm{g} / \mathrm{mL}$ \\
\hline \multicolumn{4}{|l|}{ Endothelial markers } \\
\hline Aquaporin 1 (H-55) & Endothelial & $\begin{array}{l}\text { Santa Cruz Biotechnology, } \\
\text { Santa Cruz, CA }\end{array}$ & Rabbit/10 $\mu \mathrm{g} / \mathrm{mL}$ \\
\hline Flk-1 (C-20) & Endothelial & Santa Cruz Biotechnology & Rabbit/10 $\mu \mathrm{g} / \mathrm{mL}$ \\
\hline Flt-1 (H-225) & Endothelial & Santa Cruz Biotechnology & Rabbit/10 $\mu \mathrm{g} / \mathrm{mL}$ \\
\hline
\end{tabular}

$\alpha$-SMA, $\alpha$-smooth muscle actin; Flk-1, vascular endothelial growth factor receptor 2; Flt-1, vascular endothelial growth factor receptor 1 ; Foxd-1, forkhead box D1; Gli-1, glioma-associated oncogene homolog 1; PDGFR, platelet-derived growth factor receptor; PECAM, platelet endothelial cell adhesion molecule.

\section{SYBR Green Real-Time Quantitative PCR}

MM cell expression of RNA encoding mesenchymal and endothelial markers was validated by RT-PCR amplification. Total RNA was extracted from cell lysates with the use of an RNeasy Mini Kit (Qiagen, Inc., Valencia, CA), followed by DNA digestion with the use of TURBO DNA-free Kit (Thermo Fisher), according to the manufacturers' instructions. Twenty nanograms of total RNA from each sample was amplified with specific primers with the use of the Power SYBR Green RNA-to- $\mathrm{C}_{\mathrm{T}}$ 1-Step Kit and 7900HT fast Real-Time PCR System (Applied Biosystems, Foster City, CA). Reverse transcription of RNA to cDNA step was performed at $48^{\circ} \mathrm{C}$ for 30 minutes, followed by activation with a 10-minute preincubation step at $95^{\circ} \mathrm{C}$. Amplification was performed with 40 cycles of the following program: $95^{\circ} \mathrm{C}$ for 15 seconds, $60^{\circ} \mathrm{C}$ for 1 minute, followed by melt curve. Abundance of gene expression was determined with the standard curve method and expressed relative to glyceraldehyde-3-phosphate dehydrogenase expression. Sequences of primers used are provided in Table $2 .^{20-23}$ Relative mRNA expression was calculated with the $\Delta \Delta \mathrm{C}_{\mathrm{t}}$ method.

\section{Immunofluorescence Microscopy}

For monolayer experiments, each cell line was grown to $50 \%$ to $70 \%$ confluence in multiwell plastic Lab-Tek chamber microscope slides (Nalge Nunc International, Naperville, IL) and examined for expression of mesenchymal cell markers $\alpha$-smooth muscle actin ( $\alpha$-SMA), vimentin, PDGFR- $\beta$, glioma-associated oncogene homolog 1 (Gli-1), and forkhead box D1 (Foxd-1), and endothelial cell markers VEGFR1 (Flt-1), VEGFR2 (Flk-1), and aquaporin 1 (AQP1) proteins (Table 1) with the use of previously described immunohistochemical techniques. ${ }^{8,11,12,16}$ The immunohistochemistry experiments showed expression of each positive marker protein in nearly all cells in the assay,

Table 2 RT-PCR Primers for Mice Vasculogenesis Markers

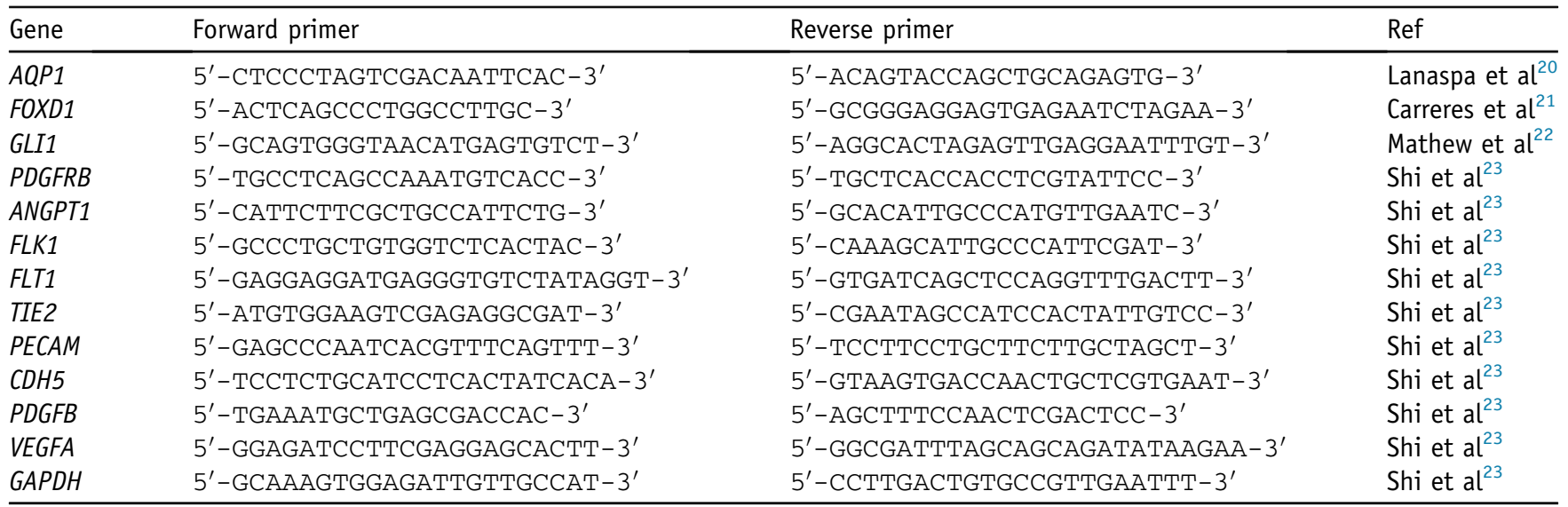


indicating that heterogeneity is minimal. Stained cells were viewed and photographed as above.

\section{Cell Proliferation}

Initial experiments were performed to establish the concentrations of PDGF-BB and VEGF-A to be used in the experiments. Freshly MM cells $\left(6 \times 10^{5}\right)$ that had undergone cell dissociation with trypsin were seeded in 6-well plates that contained complete medium, allowed to attach for 1 day. The medium was then replaced with medium that contained $0.5 \%$ serum to establish quiescence. One day later PDGF-BB or VEGF-A was added to each well at concentrations that ranged from 0 to $20 \mathrm{ng} / \mathrm{mL}$ and allowed to incubate for an additional 24 hours. At the end of the incubation time, the cells underwent cell dissociation with trypsin and were counted with a Bio-Rad TC20 automated cell counter. Optimal concentration of PDGF-BB for subsequent experiments was selected at $10 \mathrm{ng} / \mathrm{mL}$ as previously determined. ${ }^{17,18}$ Optimal concentration of VEGF-A on MM cell proliferation was determined to be $5 \mathrm{ng} / \mathrm{mL}$, similar to the maximum $\mathrm{ED}_{50}$ of $4 \mathrm{ng} / \mathrm{mL}$ established by the manufacturer for endothelial cells (R\&D Systems).

\section{Migration Assay}

A modified scratch assay was used to examine the effect of PDGF-BB and VEGF-A on MM cell migration. ${ }^{24}$ Cells were grown in 6-well culture plates to approximately $80 \%$ confluence then made quiescent as described above. Wounds were generated in each well by lightly scratching a straight line down the center of the well with the use of a $10-\mu \mathrm{L}$ pipette tip. The wells were washed with PBS to remove displaced cells. Edges of the original wound were marked by a dot on the underside of the plate. Then a serumfree medium that contained VEGF-A or PDGF-BB was added. Images were taken at 0 and 8 hours with the use of an Olympus CK40 inverted microscope equipped with a Nikon 6300 digital camera. Migration was assessed by measuring the closure of the space using digital image analysis software Image Pro Plus version 4.5 (Media Cybernetics, Rockville, MD) calibrated to a stage micrometer.

\section{Vasculogenesis Assay}

Endothelial tube formation, characteristic of both angiogenesis and vasculogenesis, was assessed with commercially available Angiogenesis plates (micron slides; IBIDI $\mathrm{GmbH}$, Munich, Germany; catalog number 160260). Vasculogenesis was examined with and without VEGF or PDGF-BB (BD Biosciences, Bedford, MA) to explore the ability of MM cells to undergo tube formation on the surface of Matrigel. ${ }^{25}$ The inner well of the slide was filled with $10 \mu \mathrm{L}$ of Matrigel and incubated at $37^{\circ} \mathrm{C}$ for 30 minutes, allowing the gel to polymerize. The MM cells underwent cell dissociation with trypsin, washed with sterile PBS, counted, and then placed in media that contained PDGF-BB $(10 \mathrm{ng} / \mathrm{mL})$ or VEGF $(2.5$ and $5 \mathrm{ng} / \mathrm{mL})$. Fifty microliters of the cell suspension that contained 10,000 cells was gently applied to the upper well by pipette tip. Control wells were seeded with cells in media without growth factor. The plate was incubated at $37^{\circ} \mathrm{C}$ and $5 \% \mathrm{CO}_{2}$ as usual. Images were taken 9 hours after application of cells, and the number of tubes, branching points, and loops were counted with Wimasis WimTube image analysis software (Onimagin Technologies SCA, Córdoba, Spain).

\section{Effect of VEGF-A and PDGF-BB on MM Cell Vasculogenesis in 3D Sea Sponge Scaffolds}

Additional experiments were performed with natural sea sponges as $3 \mathrm{D}$ scaffolds $^{26}$ to explore a direct effect of VEGF-A and PDGF-BB on MM vasculogenesis in vitro. Sea sponges were obtained from Everholder Products, LLC (Anaheim, CA) and cut in uniform $3-\mathrm{mm}^{3}$ pieces and sterilized by autoclave. The sponges were equilibrated with DMEM that contained $10 \%$ fetal bovine serum for 2 hours. MM cells were grown to $75 \%$ confluence, incubated with DMEM with or without VEGF-A or PDGF-BB for 2 hours, and then underwent cell dissociation with trypsin and placed in a sterile beaker at a density of $10^{6}$ cells $/ \mathrm{mL}$. The sponges were individually immersed in the cell suspension, gently compressed and released using sterile coverslip forceps to draw the cells into the matrix, and then incubated undisturbed for 2 hours to allow cell attachment. The sponges were placed in separate magnetic spinner flask bioreactors, one containing complete DMEM medium as control and the others with medium supplemented with VEGF-A or PDGF$\mathrm{BB}$. The bioreactors were placed on a magnetic stirrer set at $50 \mathrm{rpm}$ within an incubator maintained at $37^{\circ} \mathrm{C}$ in $5 \% \mathrm{CO}_{2}$. Medium was changed every other day. The sponges were removed at 2, 4, 6, or 8 days and fixed in neutral buffered formalin overnight for subsequent histologic analysis.

Additional experiments were conducted to explore if co-culture of MM and UB cells in sea sponges organize into differentiated structures as previously reported in Matrigel implants. ${ }^{11} \mathrm{MM}$ and UB cells were mixed in equal number and seeded into eight sea sponges as described above. Half of the seeded sponges were incubated in bioreactors in vitro and the other half were inserted subcutaneously at the nape of the neck of severe combined immune deficient (SCID) mice as previously described. ${ }^{11}$ The sponges were removed after 8 days, fixed in formalin, then processed for microscopic evaluation in hematoxylin and eosin-stained slides.

\section{Migration of MM Cells in 3D in Matrigel}

Cibacron Blue Agarose beads (Santa Cruz Biotechnology, Santa Cruz, CA) were impregnated with VEGF-A or PDGF-BB as described by Young et al. ${ }^{27}$ Briefly, the beads were washed two times in PBS, then incubated with $5 \mathrm{ng}$ / $\mathrm{mL}$ VEGF-A or $10 \mathrm{ng} / \mathrm{mL}$ PDGF-BB for 2 hours at $4^{\circ} \mathrm{C}$. 
Controls consisted of diluent $(4 \mathrm{mmol} / \mathrm{L} \mathrm{HCl}$ in $0.1 \%$ bovine serum albumin without growth factor). The beads were briefly rinsed with PBS, suspended with $0.5 \times 10^{6}$ cells, then combined with an equal volume of cold Matrigel MM and immediately injected subcutaneously in the nape of the neck of 6-week-old ICR-SCID mice (Taconic Farms, Inc., Hudson, NY) as previously described..$^{11}$ Ten days later, the implants were removed and fixed or frozen for subsequent morphologic analysis and assessment of migration and cell differentiation. All animal protocols were performed in accordance with NIH's Guide for the Care and Use of Laboratory Animals ${ }^{28}$ and reviewed by the University of Texas Health Science Center Institutional Animal Care and Use Committee.

\section{D Co-Culture of MM and UB Cells in Matrigel}

Mouse kidney progenitor cells were grown in combination in 3D culture in Matrigel (BD Biosciences) implants as previously described. ${ }^{11}$ Co-culture of MM and UB cells was performed by mixing in Matrigel and immediately injected in ICR-SCID mice as above. Ten days later, the implant was excised and frozen or fixed for subsequent histologic analysis.

Inhibition of Vasculogenesis in MM and UB Co-Culture by Interference with PDGF-BB-Cell Interactions

The above studies showed that PDGF-BB stimulated MM cell proliferation, migration, and vasculogenesis in angiogenesis and sponge experiments (see Results). We next used the 3D Matrigel implant model in SCID mice to explore a role for PDGF-BB in vasculogenesis generated by $\mathrm{MM}$ and UB cells in co-culture. MM and UB cells were co-cultured as above, except rabbit anti-PDGF-BB neutralizing antibody (IgG, AF-220-NA; R\&D Systems) was added to the cells before mixing with Matrigel to make a final concentration of $0.3 \mu \mathrm{g} / \mathrm{mL}$ in the implant. Controls received equal concentrations and volumes of IgG in PBS in place of antibody or growth factor diluent. The Matrigel/cell mixture was injected in SCID mice, and then 10 days later the implants were removed and fixed or frozen for morphologic analysis and assessment of cell differentiation. In separate studies, excess PDGF-BB was added to the Matrigel before addition of UB and MM cells as a means to disrupt a potential chemotactic gradient and to inhibit MM cell migration toward UB cells. Similar Matrigel experiments were not performed with VEGF-A because this growth factor had no effect on migration or 3D vasculogenesis assays; thus, it was not expected to influence vasculogenesis MM + UB co-culture.

\section{Vasculogenesis in UB + MM Co-Culture: Interference with PDGFR- $\beta$}

Two methods were used to examine the effects of interfering with PDGFR- $\beta$ on vasculogenesis in 3D co-culture: pharmacologic inhibition of PDGFR- $\beta$ with the use of imatinib mesylate (Gleevec; Novartis Pharma AG, Basel, Switzerland) on MM + UB cells in Matrigel implants and the use of PDGFR- $\beta^{-/-}$MM cells ${ }^{17,18}$ in place of wild-type MM cells in combination with UB cells in 3D co-culture. Imatinib mesylate (Novartis Pharma AG) an established inhibitor of PDGFR- $\beta^{29}$ was added to make a final concentration of $10 \mathrm{ng} / \mathrm{mL}$ to $\mathrm{MM}$ and UB cells immediately before suspension in Matrigel. Diluent was used in place of imatinib mesylate as control. In separate experiments, PDGFR- $\beta^{-1-}$ MM cells were combined with UB cells and suspended in Matrigel implants and compared with wildtype MM cells plus UB cells.

\section{Histologic Analysis}

Implants and sponges were fixed in $10 \%$ neutral-buffered formalin overnight, then processed for paraffin embedment, cutting, and staining with hematoxylin and eosin. In addition, cells grown in 3D in Matrigel were examined by immunohistochemistry for protein markers outlined above. For these studies, the implants and sponges were lightly fixed in formalin for 2 hours, rinsed with PBS, placed in 10\% gelatin, and allowed to set overnight at $4{ }^{\circ} \mathrm{C}$, then snap-frozen in liquid nitrogen for subsequent cryosectioning. Dual-label immunofluorescence was used in some studies to assess relative epithelial and mesenchymal expression of the individual marker proteins with the use of fluorescence staining techniques. ${ }^{11,30}$

\section{Electron Microscopy}

In selected experiments, Matrigel implants that contained kidney progenitor cells in organoids, beads in migration studies, and sea sponges were examined by electron microscopy. At termination of each experiment, small portions of the implants or sponge were diced into $<1 \mathrm{~mm}^{3}$ and fixed with $4 \%$ paraformaldehyde, $1 \%$ glutaraldehyde at $4^{\circ} \mathrm{C}$ overnight. The tissue pieces were processed for plastic embedment with the use of routine methods and examined as previously described. ${ }^{11}$

\section{Statistical Analysis}

Data are expressed as means \pm SEM, unless otherwise stated. All experiments were repeated at least three times. Experiments were analyzed by one-way analysis of variance, followed by Newman-Keuls multiple comparison post hoc test performed by GraphPad Prism 5 software (GraphPad Software, La Jolla, CA). Significance was assigned at $P \leq 0.05$.

\section{Results}

MM Cells Express Mesenchymal and Endothelial Cell Markers

We previously characterized the MM cells as a mesenchymal phenotype that expressed cell markers $\alpha$-SMA, 
vimentin, PDGFR- $\beta$ in $2 \mathrm{D}$ culture. ${ }^{11,17,18}$ Co-culture of MM and UB cells in 3D Matrigel implants showed that the cells organized around the periphery of UB cells to form capillary-like structures and expressed endothelial markers AQP1 and platelet endothelial cell adhesion molecule. ${ }^{11}$ Because the cells acquired endothelial characteristics, immunoblotting and immunofluorescence microscopy were used to examine in more detail the expression of specialized endothelial markers. The results showed that the MM cells expressed mesenchymal markers vimentin, $\alpha$-SMA, and PDGFR- $\beta$ (Figures 1 and 2). In addition, the MM cells expressed Gli-1 and Foxd-1 embryonic markers for

\section{A Mesenchymal Markers}

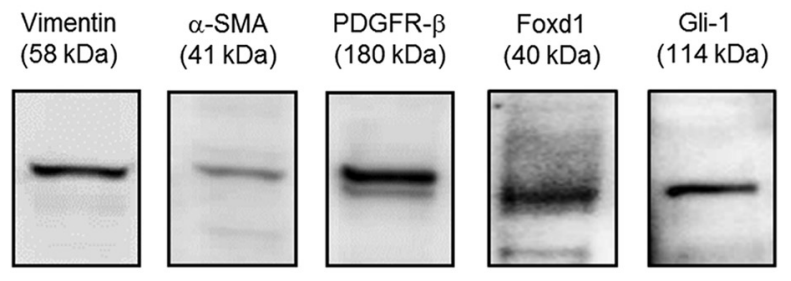

\section{B Endothelial Markers}

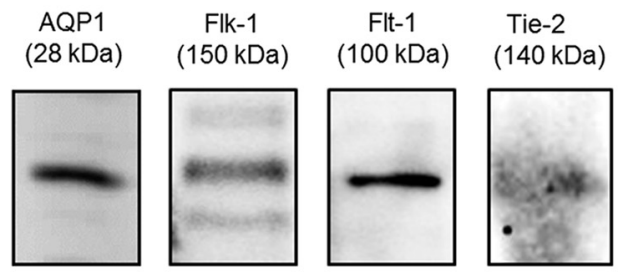

\section{Ac-LDL Endocytosis}

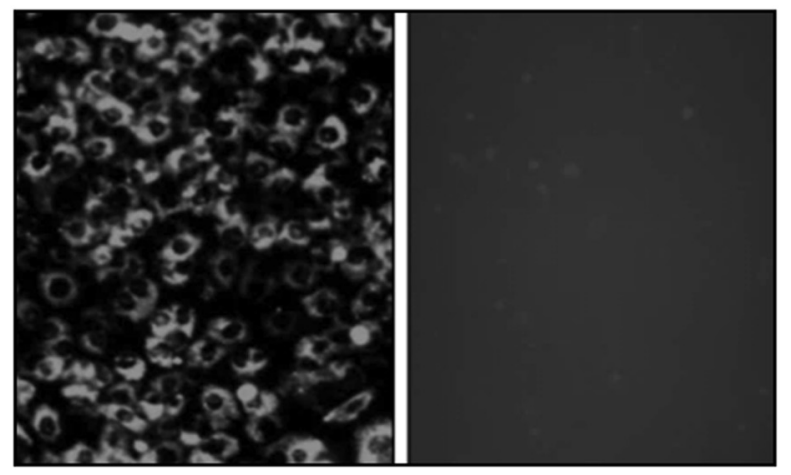

Figure 1 Metanephric mesenchymal (MM) cells express both mesenchymal and endothelial characteristics. MM cell lysates were examined by immunoblotting for expression of mesenchymal and endothelial markers. A and B: MM cells express mesenchymal marker proteins vimentin, $\alpha$-smooth muscle actin ( $\alpha$-SMA), platelet-derived growth factor receptor (PDGFR)- $\beta$, forkhead box D1 (Foxd1), and glioma-associated oncogene homolog 1 (Gli1) (A), as well as endothelial markers aquaporin 1 (AQP1), Flk-1 (vascular endothelial growth factor receptor 1), Flt-1 (VEGFR2), and Tie-2 (angiopoietin receptor) (B). C: MM cells also endocytose acetylated low-density lipoprotein (Ac-LDL), a functional characteristic of endothelial cells. Original magnification, $\times 20(\mathrm{C})$. pericytes and kidney stromal mesenchymal cells, respectively (Figure 1). The MM cells also expressed endothelial cell proteins, including Flt-1 (VEGF-R1), Flk-1 (VEGF$\mathrm{R} 2$ ), Tie2 (angiopoietin receptor), and AQP1, a marker for early capillary development (Figures 1 and 2). In addition, the MM cells endocytosed Ac-LDL, a functional marker for endothelial cells (Figure 1). To substantiate the immunoblotting and histochemistry findings, RT-PCR on RNA extracted from MM cell lysates was performed. The results showed that MM cells express mRNA encoding both mesenchymal and endothelial markers (Figures 3 and 4). Collectively, these results indicated that the MM cells expressed cell phenotypic characteristics of both mesenchymal and endothelial cells and were consistent with an interpretation that these cells may be primitive angioblasts with the potential to differentiate into specialized vascular structures.

\section{VEGF-A, PDGF-BB, and Receptor Expression in MM and UB Cells in 2D Culture}

MM cells undergo vascular organization when grown with UB cells 3D co-culture; thus, the expression profiles of two of the predominant vasculogenesis factors VEGF-A and PDGF-BB and their cognate receptors in both cell types were examined with immunoblotting and RT-PCR. The results showed that UB cells expressed PDGF-BB chain, but not PDGFR- $\beta$ (Figure 4A). Conversely, MM cells expressed PDGFR- $\beta$, but not PDGF-BB. Similarly, UB cells expressed VEGF-A, but not Flk-1, and MM cells expressed Flk-1 and small amounts of VEGF (Figure 4A). Similar results were observed for RNA encoding these proteins with the use of RT-PCR (Figure 4B) Taken together, these studies indicated that the two cell types have the machinery for directional induction of vasculogenesis by PDGF-BB and/or VEGF-A.

\section{Cell Response to PDGF-BB or VEGF-A in 2D Monolayer}

Previous studies showed that mouse MM cells proliferate and migrate in response to PDGF-BB ${ }^{17,18}$; however, the response of these cells to VEGF-A has not been examined. These present studies verified that PDGF-BB stimulated $\mathrm{MM}$ cell proliferation in a dose-dependent manner relative to diluent controls (Figure 5A). Similarly, VEGF-A stimulated MM cell proliferation (Figure 5B). In addition, PDGF$\mathrm{BB}$ and VEGF-A stimulated MM cell migration in 2D scratch assays (Figure 5C). Growth of MM cells on the surface of Matrigel in angiogenesis assays resulted in tube formation, branching points, and loops typical of endothelial growth on this matrix (Figure 6). PDGF-BB stimulated a 2.5-fold increase in MM cell tube formation, number of branching points, and loops versus diluent on Matrigel substrata in angiogenesis assays, whereas VEGF-A had no additional effect. 

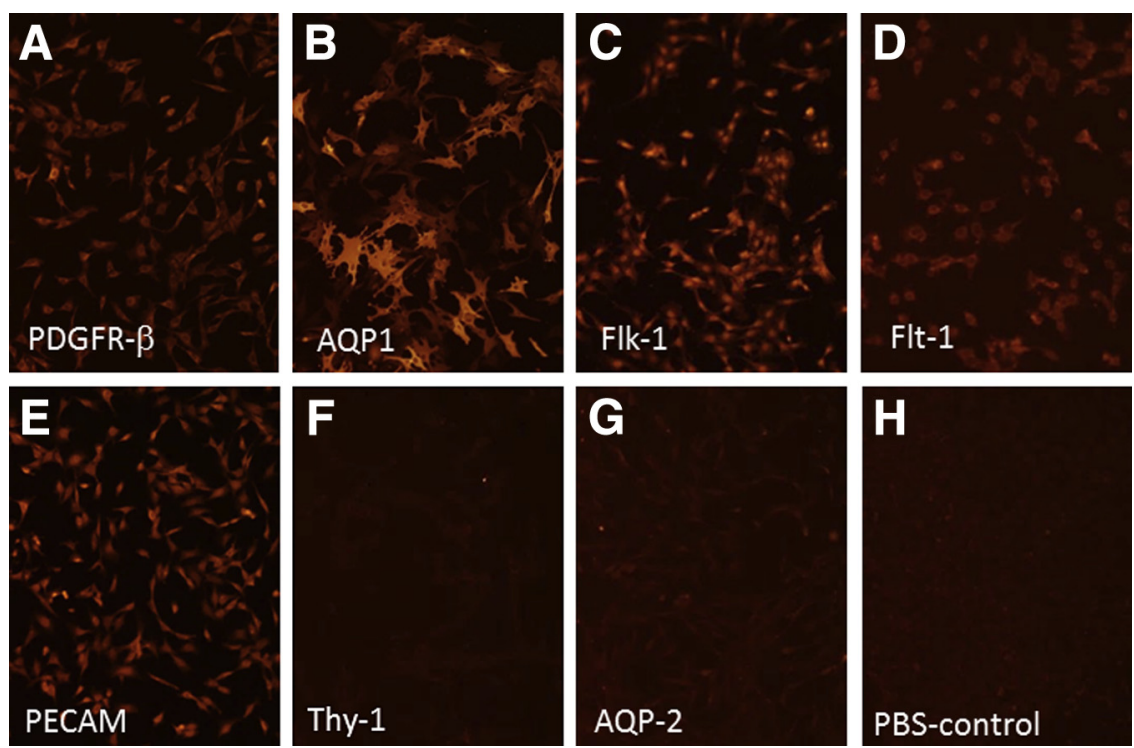

Figure 2 Metanephric mesenchymal (MM) cell expression of selected mesenchymal and endothelial markers by immunohistochemistry. A-E: MM cells express mesenchymal markers $\alpha$-smooth muscle actin ( $\alpha$-SMA), vimentin ${ }^{11}$ (not shown), and platelet-derived growth factor receptor (PDGFR)- $\beta$ (A) as well as endothelial markers aquaporin 1 (AQP1) (B), Flk-1 (vascular endothelial growth factor receptor 1; VEGFR1) (C), Flt-1 (VEGFR2) (D), and platelet endothelial cell adhesion molecule (PECAM) (E). F-G: The cells do not stain for Thy-1 (F), the ureteric bud (UB) marker AQP-2 (G), or with phosphate-buffered saline (PBS) as a negative control (H). Original magnification, $\times 10(\mathbf{A}-\mathbf{H})$.

\section{Effect of VEGF-A and PDGF-BB on Vasculogenesis by MM Cells Grown ex Vivo in 3D Sea Sponges}

Because growth of cells in a 3D microenvironment allows complex cell-cell and cell-matrix interactions that cannot be attained in monolayer, the effect of VEGF-A and PDGF-
BB on MM cells in sea sponge scaffolds was examined. At 0 hour, MM cells were present as intermittent monolayers along the contours of the walls of the sponge. The cells grown in complete medium increased in number by 2 days, forming continuous monolayers or frequent double-layered profiles that resembled capillaries along the edges of the wall contours
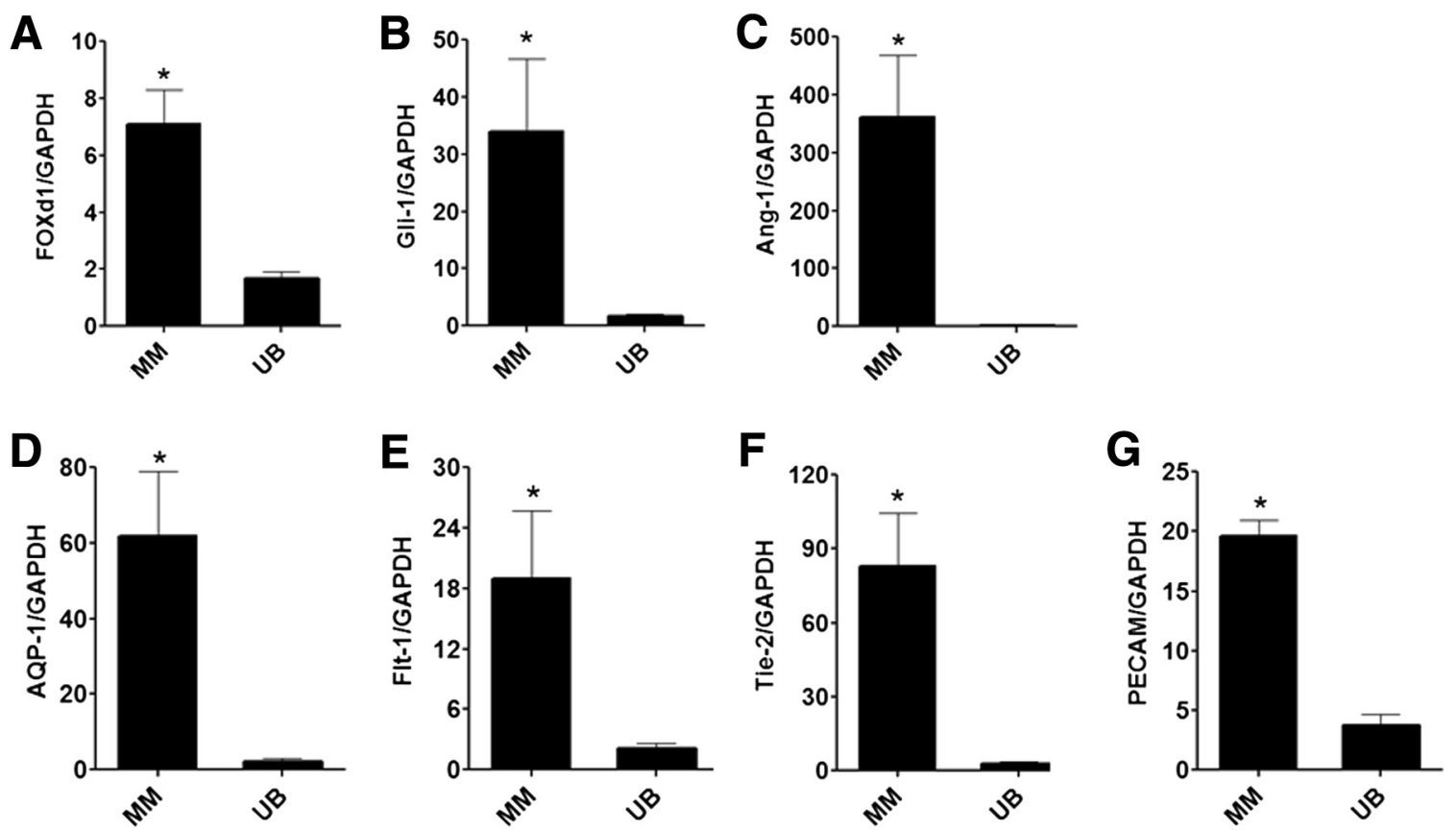

Figure 3 Metanephric mesenchymal (MM) cell expression of RNA encoding mesenchymal and endothelial markers by RT-PCR. Total RNA was extracted from MM and ureteric bud (UB) cell lysates and reverse transcribed to synthesize CDNA with the use of the SYBR Green method. Ratio of cDNA transcript of marker: glyceraldehyde-3-phosphate dehydrogenase (GAPDH) is shown for each cell line. The results show high transcript levels of mesenchymal markers forkhead box D1 (Foxd1), glioma-associated oncogene homolog 1 (Gli-1), and ANG-1 (A-C), as well as endothelial markers aquaporin 1 (AQP1), Flt-1 (vascular endothelial growth factor receptor 1; VEGFR1), Tie-2 (angiopoietin receptor), and platelet endothelial cell adhesion molecule (PECAM) (D-G) in MM cells relative to UB cells. Data are expressed as means \pm SEM. $n=3$ independent experiments. ${ }^{*} P<0.05$ versus UB cells. Ang- 1 , angiopoietin 1. 
A

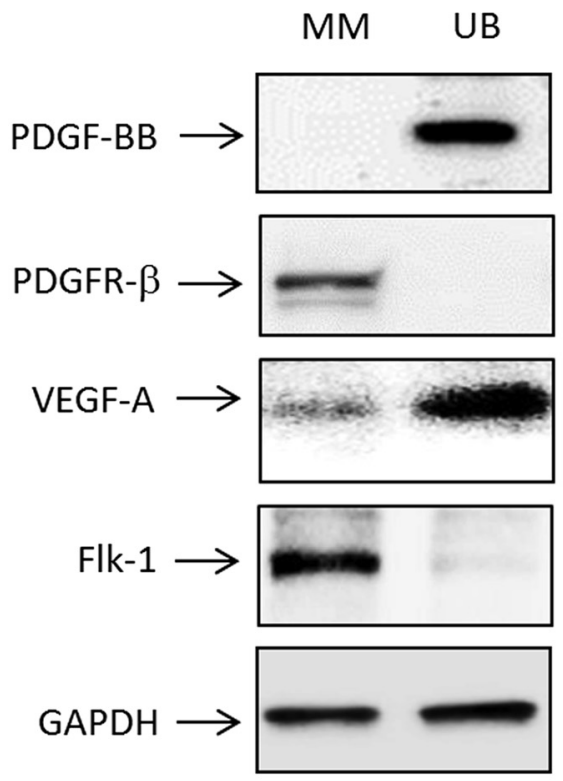

B

RT-PCR
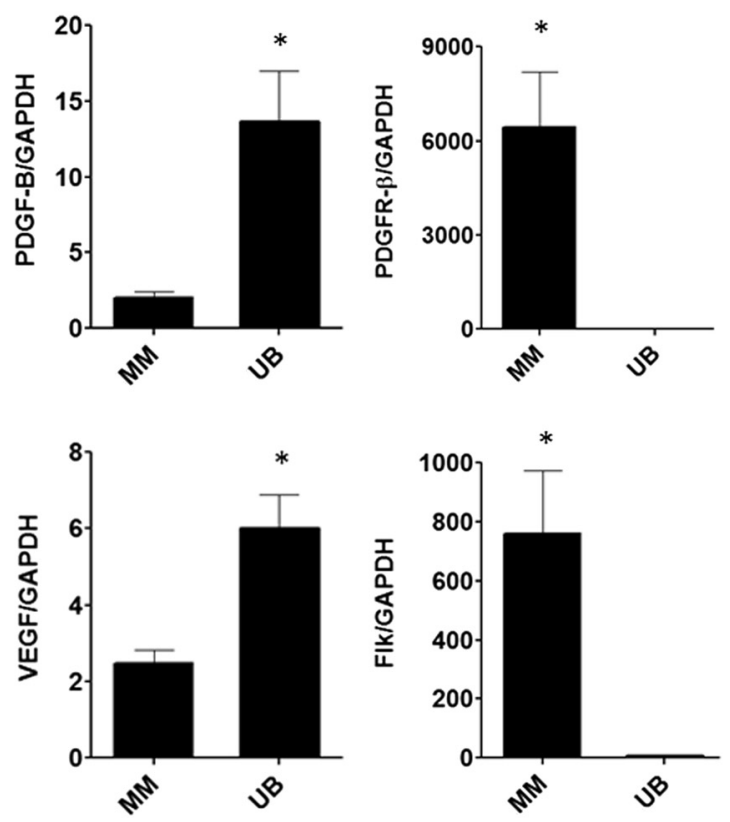

Figure 4 Directional induction of metanephric mesenchymal (MM) cell vasculogenesis. MM cells express platelet-derived growth factor B chain (PDGF-BB) and vascular endothelial growth factor (VEGF)-A receptors [PDGF receptor (PDGFR)- $\beta$ and VEGF receptor 2 (Flk-1)]. Conversely, ureteric bud (UB) cells express the cognate ligands. Immuoblotting (A) and RT-PCR (B). Data are expressed as means \pm SEM. $n=3$ independent experiments. ${ }^{*} P<0.05$ MM cells versus UB cells. GAPDH, glyceraldehyde-3-phosphate dehydrogenase.

of the sponge at 4, 6, and 8 days (Figure 7, A and G). Cells in sponges treated with VEGF-A increased in number, forming large homogenous nodules without complex organization (Figure 7B). Sponges treated with PDGF-BB showed incremental increases in the number of cells, and the complexity of cytoplasmic extensions over time when the dual-layered profiles observed at 2 days had grown into large networks of interconnected cells (Figure 7, C-I). Frequently, the arrangement of the cells within the network resembled larger vessels with lumens lined by thin attenuated cells. When
Proliferation

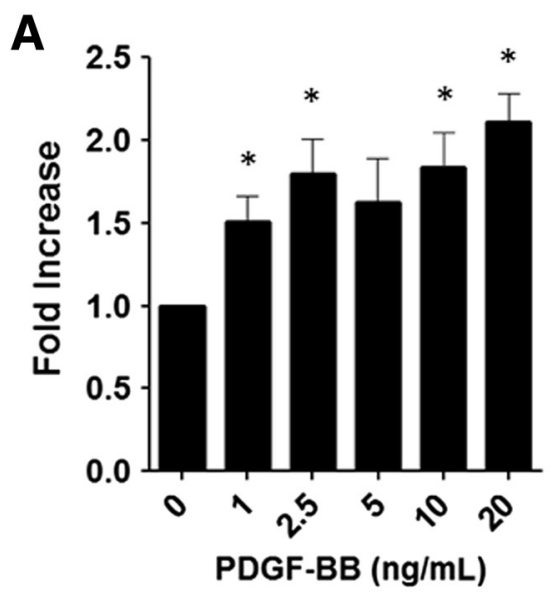

B

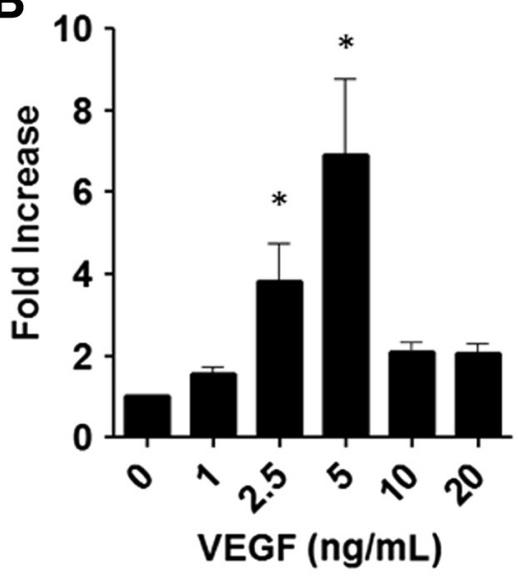

Migration

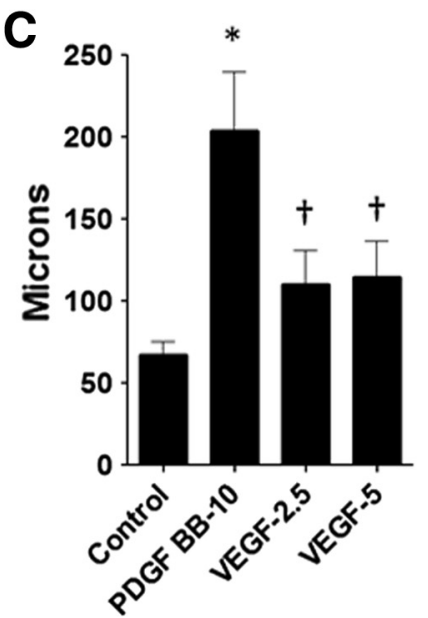

Figure 5 Metanephric mesenchymal (MM) cell proliferation and migration in response to platelet-derived growth factor B chain (PDGF-BB) and vascular endothelial growth factor (VEGF)-A. A: MM cell proliferation is dose dependent in response to 1 to $20 \mathrm{ng} / \mathrm{mL}$ PDGF-BB. B: MM cell proliferation peaks at $5 \mathrm{ng} / \mathrm{mL}$ VEGF-A. C: MM cell migration is most robust in response to PDGF-BB relative to VEGF-A. Data are expressed as means \pm SEM. $n=3$ independent experiments. ${ }^{*} P<0.05$ basal conditions versus each growth factor; ${ }^{\dagger} P<0.05$ PDGF-BB versus VEGF-A. 

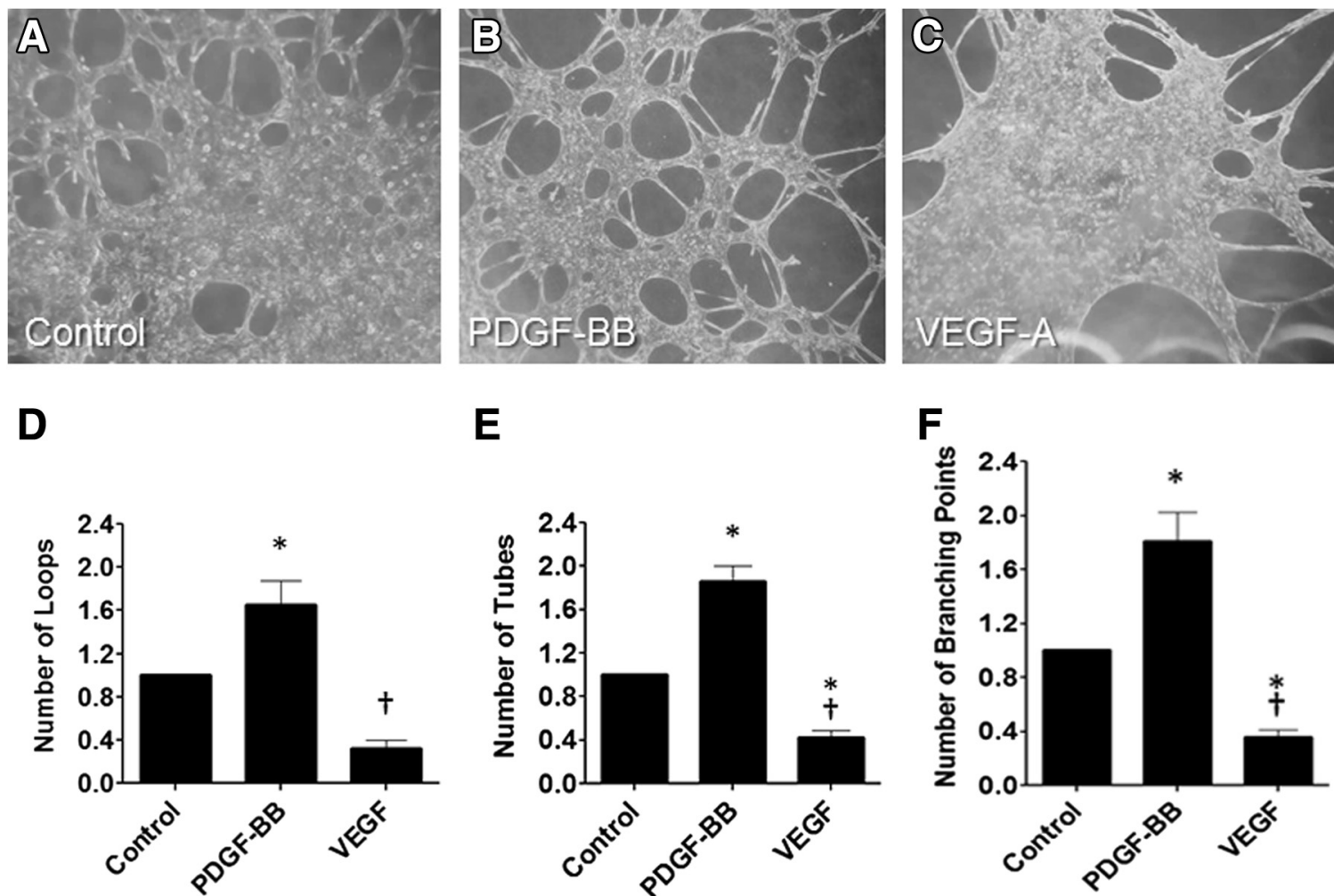

Figure 6 Metanephric mesenchymal (MM) cells form tubes in angiogenesis assay. MM cells were plated on Matrigel in micron-slide angiogenesis plates with and without vascular endothelial growth factor (VEGF)-A $(2.5$ and $5.0 \mathrm{ng} / \mathrm{mL}$ ) or platelet-derived growth factor B chain (PDGF-BB; $10 \mathrm{ng} / \mathrm{mL})$ and incubated for 8 hours. A-C: Phase contrast revealed that the number of loops, tubes, and branching points were accentuated by PDGF-BB (B) but decreased after incubation with VEGF-A (C) relative to phosphate-buffered saline (PBS) controls (A). D-F: Measured values by image analysis of the loops, tubes, and branching points for each condition are illustrated, respectively. ${ }^{\star} P<0.05$ versus control; ${ }^{\dagger} P<0.05$ versus PDGF-BB. Original magnification, $\times 10$ (A-C).

viewed by electron microscopy, the cells within the network were dendritic-like with numerous long cytoplasmic extensions often touching adjacent cells (Figure 7, G and H). Many of the cells contained vacuoles (Figure $7 \mathrm{H}$ ) similar to those reported in endothelial cells grown in collagen matrices and attributed to the cell-hollowing mechanism of endothelial lumen formation. ${ }^{31,32}$ Often, the cytoplasmic vacuoles opened to the cell surfaces to create narrow intracellular cytoplasmic bridges and long cytoplasmic extensions with varying sized curvatures (clefts). The cells were more compact and attenuated near luminal borders of larger structures (Figure 7I). The cells within the sponges expressed Flk-1 by immunohistochemistry, particularly in areas that formed continuous lumens (Figure 7, D and E). MM and UB cells grown in co-culture in sea sponges in vitro resulted in a similar network of interconnected MM cells between low profile epithelial linings (Figure 7J). Co-culture of the cells in sea sponges in vivo formed well-developed polarized UB epithelial profiles surrounded by an extensive network of interconnected MM cells (Figure 7K). However, the UB cells in the sponges were not surrounded by organized capillarylike profiles as previously reported in Matrigel implants. ${ }^{11}$ These observations suggest that matrix proteins present in the Matrigel may be necessary for more complex vascular development.
Migration of MM Cells in Response to VEGF-A or PDGF$\mathrm{BB}$ in 3D Matrigel Implants

Because PDGF-BB stimulated MM cell migration and proliferation in 2D monolayer, ${ }^{17,18}$ the effect of these growth factors on MM cell migration in 3D Matrigel implants with cells dispersed with VEGF-A- or PDGF$\mathrm{BB}$-impregnated agarose beads was examined. In this fashion, the beads would be expected to serve as perfunctory surrogates of UB cells and to release growth factors by diffusion over time, thereby stimulating migration by surrounding MM cells toward the source. The results showed that few cells migrated to control beads that contained diluent without growth factor, showing an average of seven cells on the bead surface in a partial single layer demonstrated by light microscopy (Figure 8, A and D). PDGF$\mathrm{BB}$-impregnated beads had a nearly fourfold increase in the number of MM cells on forming multiple layers over the entire surface of the bead (Figure 8, B and D). There was no difference in the number of cells on the surface of beads impregnated with VEGF-A with respect to diluent controls (Figure 8, C and D). Similarly, beads impregnated with diluent showed only single or partial layers of cells at their surface by electron microscopy (Figure 8E). Electron microscopy of PDGF-BB-impregnated beads showed 

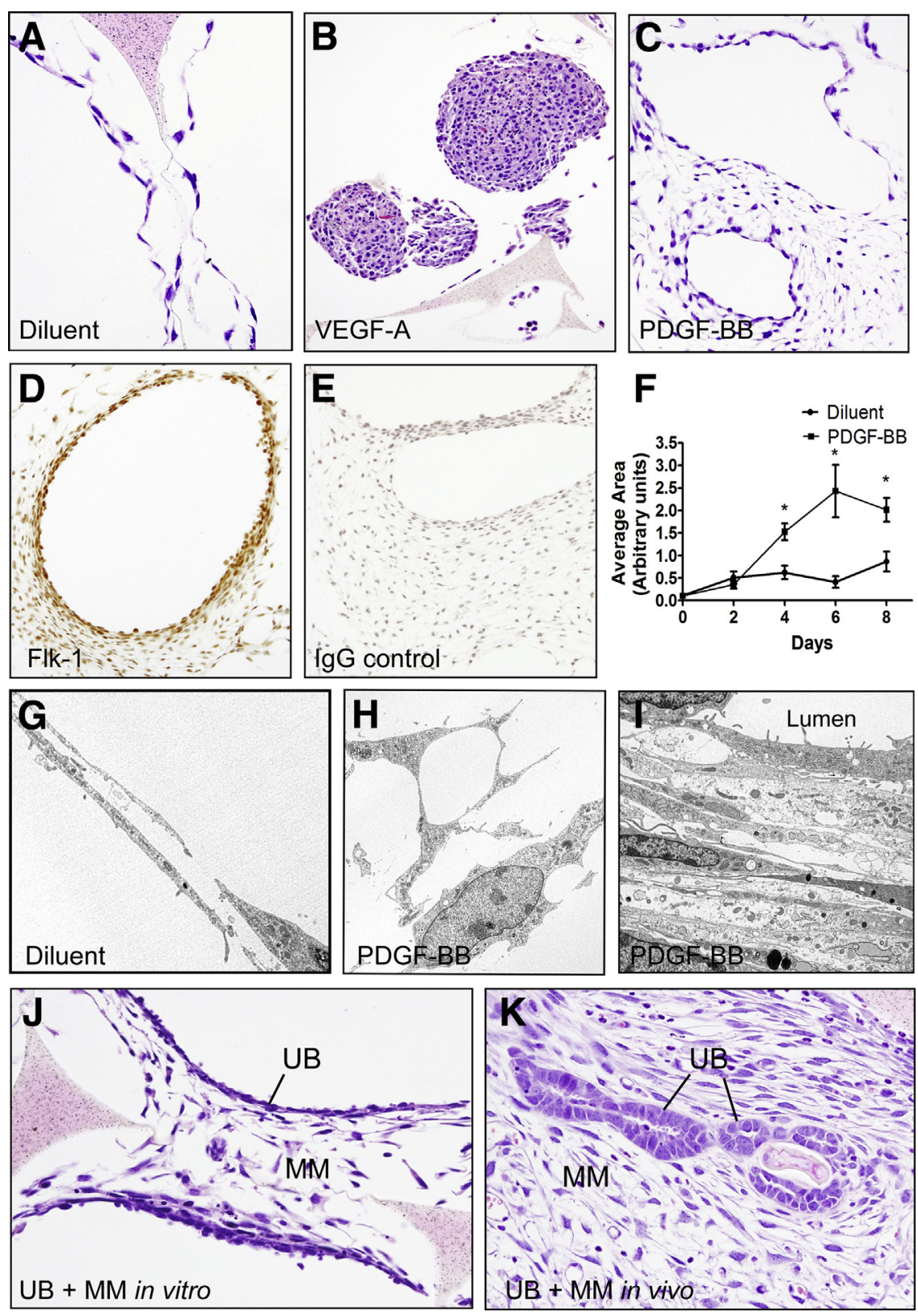

Figure 7 Vasculogenesis of metanephric mesenchymal (MM) cells grown in threedimensional (3D) culture in sea sponges. A-I: MM cells proliferate in 3D sea sponge scaffolds in response to vascular endothelial growth factor (VEGF)-A (B) and platelet-derived growth factor $B$ chain (PDGF-BB) (C-I) relative to diluent controls (A). However, only PDGF-BB stimulates vascular profiles characterized by large cyst-like structures with lumens lined with VEGF receptor 2 (Flk-1) + MM cells and a network of arborized cells (C-E). G: By electron microscopy, MM cells incubated with diluent show long attenuated capillarylike profiles often with lumens. H: The arborized MM cells after incubation with PDGF-BB show cytoplasmic extensions and numerous vacuoles proposed by others to be a mode of capillary lumen formation. I: Profiles of cyst-like structures show long attenuated cells with microvilli at the surface projecting into the lumen above several layers of attenuated cells similar in appearance to vascular smooth muscle cells. J and K: Three-dimensional (3D) co-culture of MM and ureteric bud (UB) cells in sea sponges in vitro $(\mathbf{J})$ and in implants in vivo (K) leads to epithelialization of UB cells and organization and arborization of surrounding MM cells. Data are expressed as means \pm SEM. $n=3$ independent experiments. ${ }^{*} P<0.05$ versus diluent control. Original magnification: $\times 20(\mathbf{A}, \mathbf{J}, \mathbf{K}) ; \times 10$ $(\mathbf{B}-\mathbf{E}) ; \times 5,000(\mathbf{G}-\mathbf{I})$. multiple layers of cells on the surface with numerous long projections (Figure $8 \mathrm{~F}$ ), similar to endothelial cell ultrastructure during early vasculogenesis as described in the literature. ${ }^{31-33}$

\section{D Co-Culture of MM and UB Cells in Matrigel Implants}

Experiments thus far indicated that MM cells proliferated, migrated, and organized in response to PDGF-BB; whereas VEGF-A induced minimal effect mainly in terms of cell proliferation. To further define a role for PDGF-BB in MM and UB cell co-culture, the cells were grown together in the presence of inhibitors of the PDGFR- $\beta$ and growth factor ligand. First, the two cell types were grown in Matrigel implants in SCID mice for 10 days to test their differentiation potential as previously reported. ${ }^{11}$ Culture of $\mathrm{MM}$ or UB cells in implants as single cell suspensions did not result in organized organoids (Figure 9, A and B). However, co-culture of MM and UB cells in the Matrigel implants resulted in the formation of organoids that consisted of UB-derived polarized epithelial cells surrounded by capillary-like structures formed by MM cells (Figure 9, $\mathrm{C}-\mathrm{F}$ ). Epithelial cells in the implants were stained for UB and CD markers, including cytokeratin 8 (Figure 9D), and MM cells at the periphery of tubuloid structures were stained for mesenchymal cell markers, including $\alpha$-SMA 

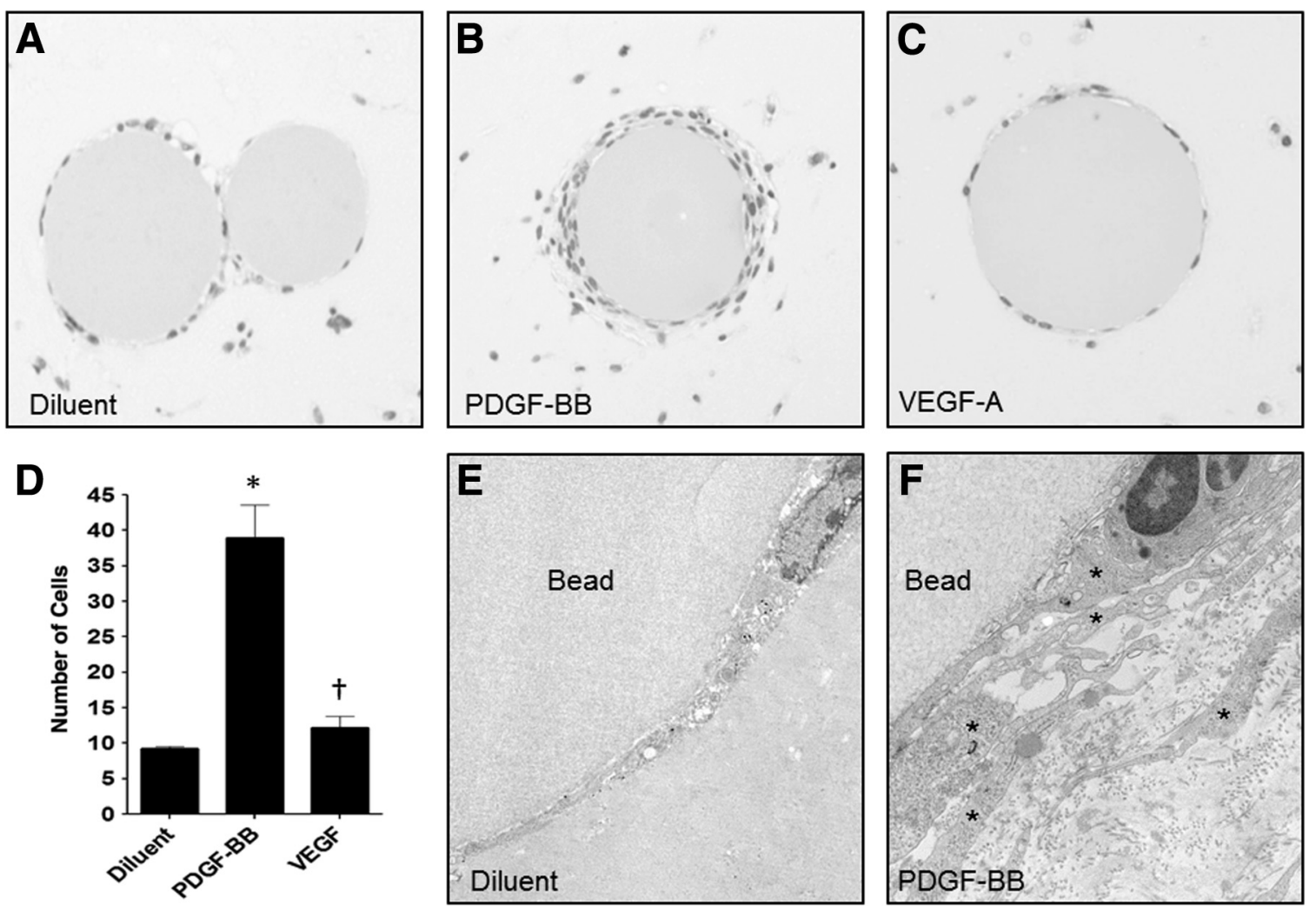

Figure 8 Metanephric mesenchymal (MM) cells migrate in response to platelet-derived growth factor B chain (PDGF-BB) in three-dimensional (3D) culture. A-C: Cibacron Blue agarose beads were impregnated with diluent (A), PDGF-BB (B), or vascular endothelial growth factor (VEGF)-A (C), suspended with MM cells in Matrigel then implanted subcutaneously in severe combined immunodeficiency (SCID) mice. Ten days later, the implants were processed for light and electron microscopy. A, D, and E: Few cells migrated to the surface of control beads treated with diluent forming at most a single layer. B, D, and F: MM cell migration toward the PDGF-BB-impregnated beads was increased fourfold, showing multiple layers around the surface of the bead. C and D: VEGF-A did not stimulate MM cell migration around the bead surface relative to control. E: Examination by electron microscopy showed a partial single layer of MM cells at the bead surface of diluent control beads. F: Numerous layered attenuated cells (asterisks) are observed at the surface of beads impregnated with PDGF-BB, often showing lumen-like spaces. ${ }^{*} P<0.05$ versus diluent control; ${ }^{\dagger} P<0.05$ versus PDGF-BB. Original magnification: $\times 10(\mathbf{A}-\mathbf{C}) ; \times 5000(\mathbf{E}) ; \times 10,000(\mathbf{F})$.

and vimentin (Figure 9E) as well as endothelial marker AQP1, an indicator for developing endothelium (Figure 9D). By electron microscopy, the mesenchymal cells that surrounded epithelial profiles had capillary-like structures frequently with lumens lined by a thin layer of flat cells that resembled developing endothelium (Figure 9F). ${ }^{33}$ Transmission electron micrographs showed focal contacts and overlapping junctions between endothelial cells as shown for developing microvessels in vitro. ${ }^{34}$

\section{Inhibition of Vasculogenesis by Neutralizing Antibody to PDGF-BB}

The immunoblotting studies of cells grown in 2D above indicated that UB cells synthesized PDGF-BB and MM cells expressed the cognate receptor PDGFR- $\beta$, indicating that a targeted chemotactic response may contribute to the organization of MM cell vasculogenesis in 3D implants. To test if PDGF-BB was naturally released from UB cells that may influence $\mathrm{MM}$ cell vasculogenesis, a neutralizing antibody to PDGF-BB was included in Matrigel implants to interfere with interactions of PDGF-BB between the two cell types. The results showed that anti-PDGF-BB antibody abolished MM cell vasculogenesis relative to controls that received IgG or diluent in place of antibody solution (Figure 10, A-C). In addition, adding excess PDGF-BB in the Matrigel implant along with the two cell types inhibited MM cell vasculogenesis relative to diluent controls (Figure 10, D-F), most likely by interruption of the chemotactic gradient and preventing directional migration of the cells.

\section{Effect of Interference with PDGFR- $\beta$ on Vasculogenesis in UB + MM Co-Culture}

The above experiment examined the effect of interference of PDGF-BB ligand on vasculogenesis in 3D Matrigel implants. In additional experiments, two methods were used to examine the effects of interfering with PDGFR- $\beta$ on vasculogenesis in UB + MM co-culture: pharmacologic inhibition of the receptor with the use of imatinib mesylate or use of PDGFR- $\beta^{-1-}$ MM cells ${ }^{17}$ in place of MM cells in combination with UB cells in 3D co-culture. The results showed that either imatinib mesylate or PDGFR- $\beta^{-1-}$ MM 

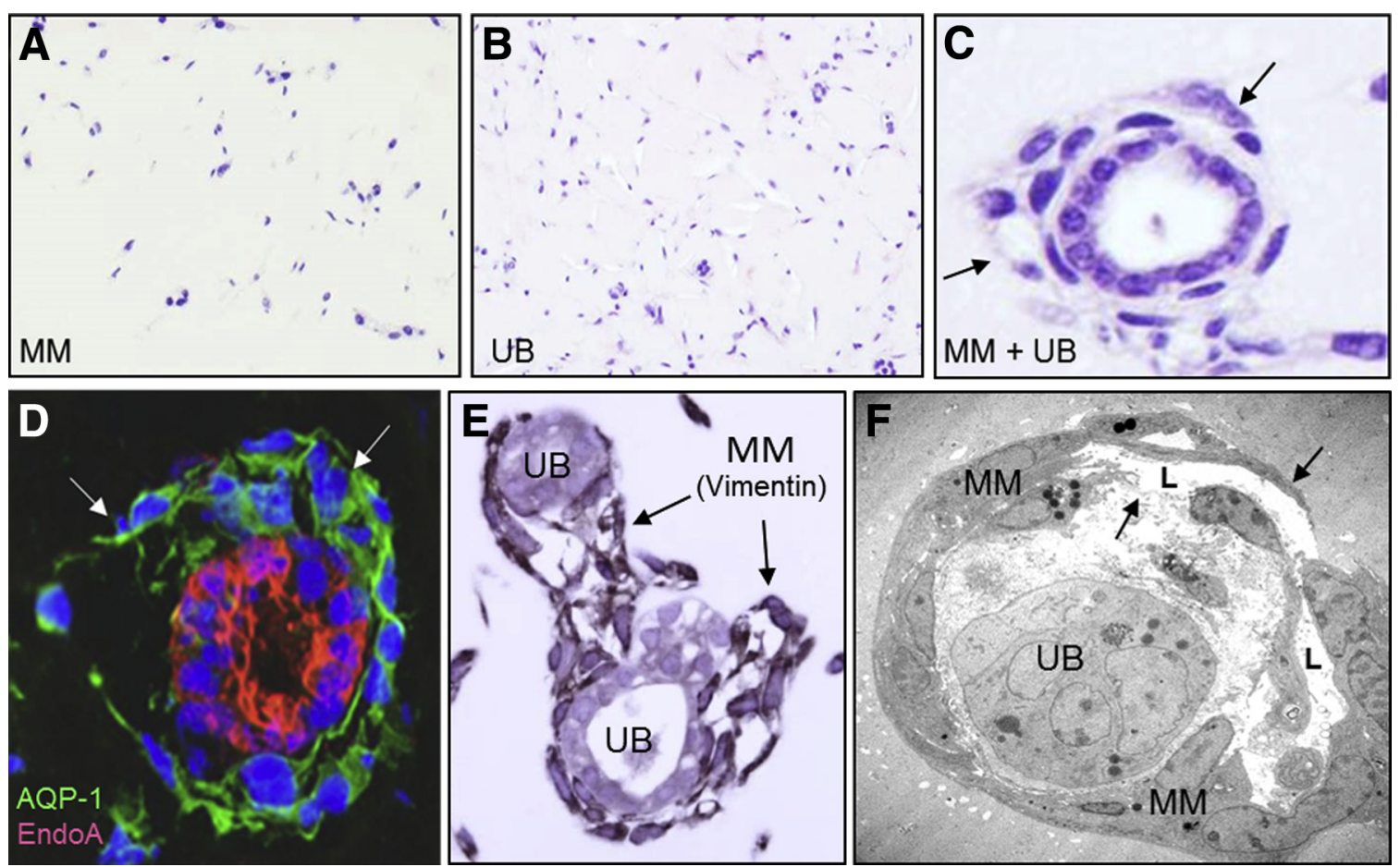

Figure 9 Three-dimensional (3D) co-culture of metanephric mesenchymal (MM) and ureteric bud (UB) cells in Matrigel implants leads to organization and simple vasculogenesis. A and B: 3D growth of MM (A) and UB (B) cells in homotypic suspensions in Matrigel implants results in little organization of the cells. C-F: When the two cell types are co-cultured, organoid profiles develop characterized by UB tubuloid epithelial structures surrounded by MM cells in capillarylike structures (arrows). D: MM cells stain with endothelial marker aquaporin-1 (AQP-1; green) surrounding EndoA cytokeratin-positive UB cells (red) in duallabel immunofluorescence. E: MM cells also stain for mesenchymal markers such as vimentin as illustrated by immunoperoxidase (brown reaction product, arrows). F: Electron microscopy reveals endothelial-like cells with attenuated profiles (arrows) and lumens (L) surrounding a UB epithelial cluster. Original magnification: $\times 10(\mathbf{A}$ and $\mathbf{B}) ; \times 40(\mathbf{C}-\mathbf{E}) ; \times 2500(\mathbf{F})$.

cells in the 3D co-culture experiments inhibited formation of organized vascular structures around UB cell profiles (Figure 11). These results along with the PDGF-BB interference studies above indicated that PDGF/PDGFR- $\beta$ cell interactions are necessary for MM progenitor cell vasculogenesis in the 3D co-culture system.

\section{Discussion}

Our previous studies provided a 3D culture model system to examine simple kidney organogenesis by MM and UB cells in co-culture ex vivo. ${ }^{11}$ The results of those studies showed reciprocal UB cell-MM cell interactions that resulted in the
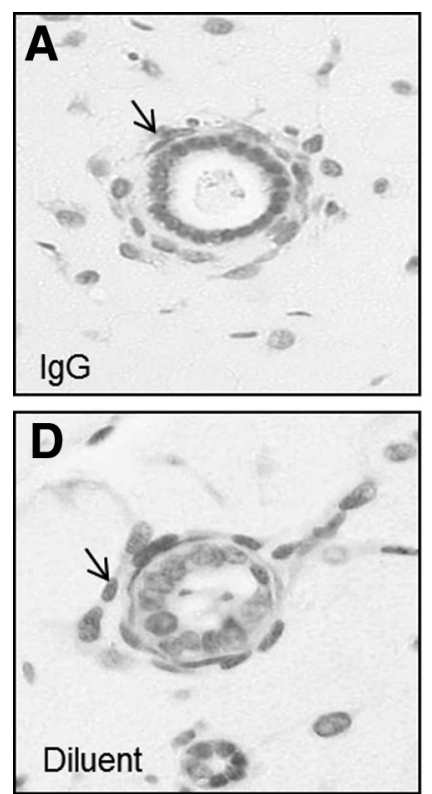
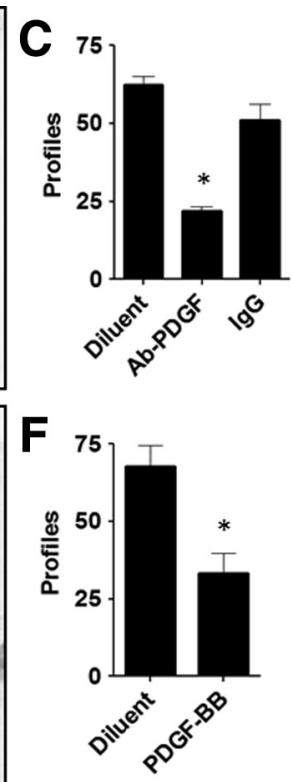

Figure 10 Neutralization of platelet-derived growth factor B chain (PDGF-BB) abrogates vasculogenesis by metanephric mesenchymal (MM) and ureteric bud (UB) cells in co-culture in Matrigel implants. A: When the two cell types are incubated with IgG, MM cells undergo vasculogenesis, indicated by the presence of numerous cells (arrow) surrounding epithelial UB profiles. B: Incorporation of PDGF-BB-neutralizing antibody with the cells in the Matrigel abrogates this effect. D and E: Similarly, MM cell vasculogenesis proceeds (arrow) when diluent is incorporated with the cells in Matrigel implants (D), whereas PDGF$B B$ interrupts the chemotactic gradient and inhibits MM cell vasculogenesis (E). ${ }^{*} P<0.05$ versus control. Original magnification, $\times 20($ A, B, D, E). 

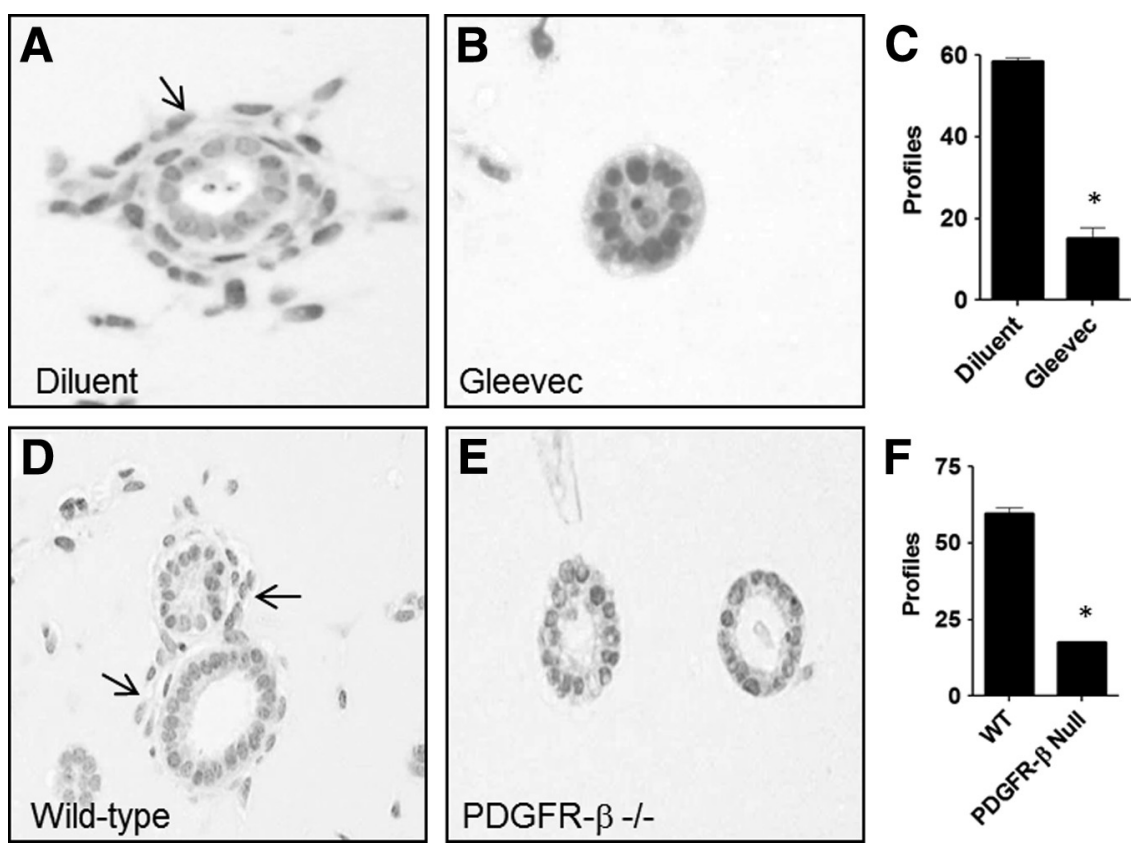

formation of a polarized CD-like epithelium surrounded by primitive capillary-like structures derived from MM cells. Here, the MM cells were further characterized and the co-culture system as well as other 3D culture formats used to examine the role of two principal effectors of vasculogenesis VEGF-A and PDGF-BB on MM cell differentiation and vasculogenesis. These present studies highlight the following novel findings: i) MM cells express both mesenchymal and endothelial phenotypic markers, suggesting that these cells are renal angioblasts with vasculogenesis potential; ii) UB cells express VEGF-A and PDGF-BB protein and MM cells express their cognate receptors, providing for a directional stimulation of MM cells toward vasculogenesis. Such a ligand/receptor arrangement for VEGF-A and PDGF-BB replicates the localization of these molecules described in vivo; iii) PDGF-BB stimulates MM cell proliferation, migration, and differentiation, whereas VEGF-A mainly affects cell proliferation; iv) PDGF-BB stimulates MM cell intracytoplasmic vacuolization and formation of attenuated cytoplasmic processes features that are parallel to endothelial development and lumen formation ${ }^{31,32}$; v) MM vasculogenesis in co-culture with UB cells can be blocked by interference with PDGF$\mathrm{BB} /$ receptor interactions; thus, growth of $\mathrm{MM}$ cells in a 3D microenvironment provides an ideal platform for further investigation of UB-MM cell interactions and mechanisms of renal vasculogenesis.

The origin of the vasculature in the metanephric kidney occurs by two processes-de novo vasculogenesis by mesenchymal cells intrinsic to the kidney as well as migration of progenitor cells from preexisting vessels external to the kidney (angiogenesis). ${ }^{6,35,36}$ A close relationship occurs between endothelial growth and differentiation and pericytes
Figure 11 Interference with platelet-derived growth factor B chain (PDGF-BB) receptor abrogates vasculogenesis by metanephric mesenchymal (MM) and ureteric bud (UB) cells in co-culture in Matrigel implants. A: When the two cell types are incubated with diluent, MM cells undergo vasculogenesis indicated by the presence of numerous cells (arrow) surrounding epithelial UB profiles. B and C: Incorporation of PDGF receptor (PDGFR)- $\beta$ inhibitor-imatinib mesylate (Gleevec; Novartis Pharma, AG, Basel, Switzerland)-abrogates this effect. D-F: Similarly, wild-type MM cells undergo vasculogenesis (arrows) in co-culture with UB cells (D), whereas PDGFR- $\beta$ null MM cells in co-culture with UB cells fail to undergo vasculogenesis (E and $\mathbf{F}) .{ }^{*} P<0.05$ versus control. Original magnification, $\times 20($ A, B, D, E).

in both modes of vascular development. ${ }^{37-39}$ The nascent vasculature is derived from endothelial progenitor cells, followed by recruitment, maturation, and stabilization of developing vessels by specialized mural pericytes. ${ }^{40}$ Endothelial cell growth and development are conventionally attributed to VEGF-A, ${ }^{41}$ whereas pericyte recruitment is attributed to PDGF-BB. ${ }^{38,40}$ However, capillary development is more complex than this simplified model because several other growth factors play formative roles during the course of vascular development and VEGF-A or PDGF-BB are each capable of cross-stimulating vascular precursors. ${ }^{9,40}$ For example, PDGF-BB alone can promote early endothelial cell differentiation, proliferation, and cord formation ${ }^{13,42}$ and is capable of stimulating endothelial cell migration, vascular sprouting, and branching of capillary-like structures in embryoid bodies. ${ }^{43,44}$

The MM cells used in this study were isolated from 11.5 days mouse embryos at a time before development of the tubular and vascular system; thus, these cells presumably have the potential to develop into either epithelial or vascular lineages. This and previous studies with MM cells in monolayer indicate that these cells have mesenchymal characteristics similar to mesangial cell and pericyte progenitors that express $\alpha$-SMA, vimentin, and PDGFR- $\beta$ and that proliferate and migrate in response to PDGF-BB by signaling pathways such as phosphatidylinositol 3-kinase, Src, and NADPH oxidase (Nox4)-derived reactive oxygen species. ${ }^{11,17,18,45}$ Indeed, the similarities between the MM and mesangial cells suggest that the latter cells are precursor cells that invade the cleft of the developing glomerulus. ${ }^{8,17,18,45}$ UB cells synthesized PDGF-BB protein, a finding that aligns with the in vivo observations that this growth factor is present in the tips of branching ureteric 
bud. ${ }^{46}$ PDGF-BB promotes MM cell migration and organization around UB cells in 3D co-culture, an effect that can be interrupted by interfering with PDGF-BB ligand or its receptor. This reciprocal arrangement suggests that the MM cells may be precursors to vascular pericytes in addition to glomerular mesangial cells. These observations are in accordance with early studies on histologic localization of PDGFR- $\beta$ and PDGF BB in developing human and mouse kidney in which the interstitial mesenchyme expresses the receptor and endothelial or tubular or glomerular epithelial cells are the site of ligand synthesis ${ }^{47}$ and implicate a directed induction of MM cell migration, homing, and maturation of the developing pericytes and mesangium. This phenotype fits nicely with a known effect that abolition of PDGFR- $\beta$ or PDGF-BB in vivo causes lack of development of a mesangium and vascular microaneurysms ${ }^{48,49}$ whereby mesangial cells and pericytes provide support for the developing endothelium during vasculogenesis as discussed above.

Surprisingly, the MM cells have an added level of phenotypic complexity in that they additionally express endothelial markers. For example, the MM cells metabolize DiI-Ac-LDL a marker for endothelial progenitors or mature endothelial cells that is typically absent in fibroblasts, smooth muscle, pericytes, and epithelial cells. ${ }^{50}$ The MM cells also express AQP1 water channel protein known to be associated with tubular epithelium, ${ }^{51}$ but it is also functionally associated with endothelial cell migration in developing capillaries. ${ }^{52}$ Moreover, AQP1 is expressed in the developing vasculature that surrounds the $\mathrm{CD}$ system during kidney development, ${ }^{53}$ an observation that is analogous to the 3D Matrigel observations in which MM cells form a vasculature that surrounds UB progenitor cells with CD characteristics. The MM cells also express Flk-1 and Flt-1 receptors for VEGF and proliferate in response to VEGF in monolayer and 3D sponge scaffolds. Flk-1 is present on primitive angioblast precursors throughout the course of vasculogenesis and by mature endothelium. ${ }^{54-56}$ As with AQP1, Flk-1 first becomes apparent in mesenchyme that surrounds the UB in developing mouse kidney. ${ }^{36}$ Like PDGF-BB/PDGFR- $\beta$, a reciprocal distribution of message for VEGF in glomerular and CD epithelia and Flk-1 in surrounding endothelial cells has been described in the fetal kidney. ${ }^{57,58}$ Differentiating endothelial cells have also been associated with a developing $C D$ network in kidney organoids derived from human induced pluripotent stem cells. ${ }^{59}$

Altogether, these results show that the MM cells are phenotypically similar to both endothelial cells and pericytes and may represent an early primitive endothelial precursor analogous to endothelial progenitor cells capable of responding to PDGF-BB. ${ }^{42}$ Flk-1 is the earliest differentiation marker for endothelial cells ${ }^{55,56}$ and intrinsic angioblasts that bear Flk-1 are found in mouse metanephric mesenchyme on embryonic day 12, before when organized blood vessels are first observed, ${ }^{3}$ and matches the period when MM cells were isolated from the developing renal primordia. The observations that $\mathrm{Flk}-1^{+}$cells derived from embryonic stem cells can differentiate into both endothelial and mural cells and can complete vasculogenesis from a single progenitor cell type would also agree with a common angioblast cell type capable of differentiating into an entire vascular structure. ${ }^{9}$ Similarly, human pluripotent stem cells can be chemically induced to diversify into a mesodermal fate and subsequent exposure to VEGF-A or PDGF-BB results in the differentiation of either endothelial or vascular smooth muscle cells, respectively. ${ }^{60}$ Interestingly, Foxd-1-positive metanephric mesenchymal (stromal) cells may beget a heterogeneous population of mural and endothelial cell lineages. ${ }^{10,61}$ Moreover, Foxd-1/Flk-1 angioblasts are crucial in vascular development and ureteric bud branching during nephrogenesis. ${ }^{61}$ Similarly, the MM cells express Gli-1, an important transcription factor of hedgehog signaling required for differentiating endothelial precursors $^{38,62}$ as well as developing pericytes. ${ }^{63}$ Thus, it appears that during the course of vasculogenesis, early progenitor cells acquire receptors for both VEGF-A and PDGF-BB and have the ability to differentiate into both pericytes and endothelial cells. In addition, endothelial cells have been shown to be progenitors of cardiac pericytes and vascular smooth muscle cells, illustrating heterogeneous nature of vascular development. ${ }^{64}$ How these MM cells fit in the vascular phylogenic tree is not known, but the observations suggest that they are early vascular progenitor cells with potential to develop into both endothelial and pericyte phenotypes. These findings also are in agreement with previous in vivo studies in which both endothelial and mesenchymal markers colocalize within the cleft of the developing glomerulus, suggesting a common glomerular angioblast progenitor cell. ${ }^{8}$ Moreover, a burgeoning field of kidney vasculogenesis is under way, illustrating the complexity of endothelial cell progenitor lineage. ${ }^{65,66}$ How these MM cells fit into these recently described developmental origins of endothelial progenitors remains to be elucidated.

The above observations and the fact that MM cells form capillary-like structures that surround developing UB epithelium provide a culture model system that is analogous to nephrogenesis in utero. However, the MM cells are only partially responsive to VEGF-A in that the cells failed to respond to VEGF-A in vasculogenesis assay or in migration assay in 3D cell culture, suggesting that PDGF-BB may have a predominant role in the MM cell vasculogenesis in co-culture with UB cells. More insight about phenotype characteristics of the MM cells can be found in the observations that PDGF-BB induces capillary-like profiles within sea sponges and on the surface of impregnated beads in 3D culture (Figures 7 and 8). MM cells in 3D sponges formed structures remarkably similar to polygonal cells in developing metanephric interstitium, showing numerous cleft-like profiles and long attenuated cytoplasmic projections. ${ }^{67} \mathrm{By}$ electron microscopy, the MM cells exposed to PDGF-BB 
formed large intracytoplasmic vacuoles similar to the process of capillary lumen formation by endothelial cells during vasculogenesis. ${ }^{31,32}$ Of interest is the formation of long cytoplasmic extensions by a process vacuolar opening to the external aspect of the cell that we refer to as clefting. This mode of cytoplasmic attenuation and extension does not fit the conventional modes of endothelial extension and migration by formation of lamellopodia, fillopodia, invadopodia, and/or podosomes as described in the literature. ${ }^{68}$ To our knowledge, this is the first description of cytoplasmic extensions formed by consecutive clefting of intracytoplasmic vacuoles. Such clefting results in long cytoplasmic extensions that may form attenuated cytoplasm of endothelium capillaries. Of interest, MM cells forming capillary-like structures that surround differentiating UB epithelia have vacuoles and cleft-like cytoplasmic extensions similar to the cells in 3D sponges (Figure 9). ${ }^{11}$ Differentiation of the endothelium during development is promoted by mechanical forces transmitted by intravascular fluid on the establishment of blood flow. ${ }^{69}$ Thus, the influence of mechanical fluid flux on MM cells in the sponge in the spinning flask bioreactor should also be taken into account in addition to stimulatory effects of PDGF-BB.

The molecular mechanisms that initiate and guide intrarenal vascularization are fundamental questions that remain to be answered. ${ }^{35,70} 3 \mathrm{D}$ culture systems, in contrast to $2 \mathrm{D}$ culture, more realistically mimic the cellular microenvironment that exists in living tissue. The use of MM cell lines in 3D platforms will provide opportunities to broaden our understanding of renal vasculogenesis for far reaching applications such as cell physiology, drug and toxicity testing, and regenerative medicine.

\section{Acknowledgment}

We thank Dr. Jolanda Herzig (Novartis Pharma, AG) for kindly providing imatinib mesylate.

\section{References}

1. Dressler GR: The cellular basis of kidney development. Annu Rev Cell Dev Biol 2006, 22:509-529

2. Abrahamson DR: Glomerulogenesis in the developing kidney. Semin Nephrol 1991, 11:375-389

3. Robert B, St John PL, Hyink DP, Abrahamson DR: Evidence that embryonic kidney cells expressing flk-1 are intrinsic, vasculogenic angioblasts. Am J Physiol 1996, 271:F744-F753

4. Sequeira Lopez ML, Gomez RA: Development of the renal arterioles. J Am Soc Nephrol 2011, 22:2156-2165

5. Kanwar YS, Wada J, Lin S, Danesh FR, Chugh SS, Yang Q, Banerjee T, Lomasney JW: Update of extracellular matrix, its receptors, and cell adhesion molecules in mammalian nephrogenesis. Am J Physiol Renal Physiol 2004, 286:F202-F215

6. Hyink DP, Tucker DC, St John PL, Leardkamolkarn V, Accavitti MA, Abrass CK, Abrahamson DR: Endogenous origin of glomerular endothelial and mesangial cells in grafts of embryonic kidneys. Am J Physiol Renal Physiol 1996, 270:F886-F899
7. Levinson R, Mendelsohn C: Stromal progenitors are important for patterning epithelial and mesenchymal cell types in the embryonic kidney. Semin Cell Dev Biol 2003, 14:225-231

8. Ricono JM, Xu YC, Arar M, Jin DC, Barnes JL, Abboud HE: Morphological insights into the origin of glomerular endothelial and mesangial cells and their precursors. J Histochem Cytochem 2003, $51: 141-150$

9. Yamashita J, Itoh H, Hirashima M, Ogawa M, Nishikawa S, Yurugi T, Naito M, Nakao K, Nishikawa S: Flk1-positive cells derived from embryonic stem cells serve as vascular progenitors. Nature 2000, 408:92-96

10. Sims-Lucas S, Schaefer C, Bushnell D, Ho J, Logar A, Prochownik E, Gittes G, Bates CM: Endothelial progenitors exist within the kidney and lung mesenchyme. PLoS One 2013, 8: e65993

11. Velagapudi C, Nilsson RP, Lee M-J, Burns HS, Ricono J, Arar MY, Barnes VL, Abboud HE, Barnes JL: Reciprocal induction of simple organogenesis by mouse kidney progenitor cells in three-dimensional co-culture. Am J Pathol 2012, 180:819-830

12. Ye P, Habib SL, Ricono JM, Kim NH, Choudhury GG, Barnes JL, Abboud HE, Arar MY: Fibronectin induces ureteric bud cells branching and cellular cord and tubule formation. Kidney Int 2004, 66:1356-1364

13. Rolny C, Nilsson I, Magnusson P, Armulik A, Jakobsson L, Wentzel P, Lindblom P, Norlin J, Betsholtz C, Heuchel R, Welsh M, ClaessonWelsh L: Platelet-derived growth factor receptor-beta promotes early endothelial cell differentiation. Blood 2006, 108:1877-1886

14. Coultas L, Chawengsaksophak K, Rossant J: Endothelial cells and VEGF in vascular development. Nature 2005, 438:937-945

15. Ferguson JE III, Kelley RW, Patterson C: Mechanisms of endothelial differentiation in embryonic vasculogenesis. Arterioscler Thromb Vasc Biol 2005, 25:2246-2254

16. Arar M, Xu YC, Elshihabi I, Barnes JL, Choudhury GG, Abboud HE: Platelet-derived growth factor receptor beta regulates migration and DNA synthesis in metanephric mesenchymal cells. J Biol Chem 2000, 275:9527-9533

17. Wagner B, Ricono JM, Gorin Y, Block K, Arar M, Riley D, Choudhury GG, Abboud HE: Mitogenic signaling via platelet-derived growth factor beta in metanephric mesenchymal cells. J Am Soc Nephrol 2007, 18:2903-2911

18. Ricono JM, Wagner B, Gorin Y, Arar M, Kazlauskas A, Choudhury GG, Abboud HE: PDGF receptor-beta modulates metanephric mesenchyme chemotaxis induced by PDGF AA. Am J Physiol Renal Physiol 2009, 296:F406-F417

19. Grandaliano G, Choudhury GG, Poptic E, Woodruff K, Barnes JL, Abboud HE: Thrombin regulated PDGF expression in bovine glomerular endothelial cells. J Am Soc Nephrol 1998, 9:583-589

20. Lanaspa MA, Andres-Hernando A, Li N, Rivard CJ, Cicerchi C, Roncal-Jimenez C, Schrier RW, Berl T: The expression of aquaporin1 in the medulla of the kidney is dependent on the transcription factor associated with hypertonicity, TonEBP. J Biol Chem 2010, 285: 31694-31703

21. Carreres MI, Escalante A, Murillo B, Chauvin G, Gaspar P, Vegar C, Herrera E: Transcription factor Foxd1 is required for the specification of the temporal retina in mammals. J Neurosci 2011, 31:5673-5681

22. Mathew E, Collins MA, Fernandez-Barrena MG, Holtz AM, Yan W, Hogan JO, Tata Z, Allen BL, Fernandez-Zapico ME, di Magliano MP: The transcription factor GLI1 modulates the inflammatory response during pancreatic tissue remodeling. J Biol Chem 2014, 289:27727-27743

23. Shi SC, Robinson GS, Perruzzi CA, Calvo A, Desai K, Green JE, Ali IU, Smith LE, Senger DR: Molecular profiling of angiogenesis markers. Am J Pathol 2002, 161:35-41

24. Liang CC, Park AY, Guan JL: In vitro scratch assay: a convenient and inexpensive method for analysis of cell migration in vitro. Nat Protoc 2007, 2:329-333 
25. Kubota Y, Kleinman HK, Martin GR, Lawley TJ: Role of laminin and basement membrane in the morphological differentiation of human endothelial cells into capillary-like structures. J Cell Biol 1988, 107:1589-1598

26. Green D, Howard D, Yang M, Kelly M, Oreffo RO: Natural marine sponge fiber skeleton: a biomimetic scaffold for human osteoprogenitor cell attachment, growth, and differentiation. Tissue Eng 2003, 9: 1159-1166

27. Young HM, Hearn CJ, Farlie PG, Canty AJ, Thomas PQ, Newgreen DF: GDNF is a chemoattractant for enteric neural cells. Dev Biol 2001, 229:503-516

28. Committee for the Update of the Guide for the Care and Use of Laboratory Animals; National Research Council: Guide for the Care and Use of Laboratory Animals: Eighth Edition. Washington, DC, National Academies Press, 2011

29. Buchdunger E, Cioffi CL, Law N, Stover D, Ohno-Jones S, Druker BJ, Lydon NB: Abl protein-tyrosine kinase inhibitor STI571 inhibits in vitro signal transduction mediated by c-kit and plateletderived growth factor receptors. J Pharmacol Exp Ther 2000, 295: $139-145$

30. Barnes VL, Musa J, Mitchell RJ, Barnes JL: Expression of embryonic fibronectin isoform EIIIA parallels alpha-smooth muscle actin in maturing and diseased kidney. J Histochem Cytochem 1999, 47: 787-798

31. Davis GE, Camarillo CW: An alpha 2 beta 1 integrin-dependent pinocytic mechanism involving intracellular vacuole formation and coalescence regulates capillary lumen and tube formation in threedimensional collagen matrix. Exp Cell Res 1996, 224:39-51

32. Davis GE, Stratman AN, Sacharidou A, Koh W: Molecular basis for endothelial lumen formation and tubulogenesis during vasculogenesis and angiogenic sprouting. Int Rev Cell Mol Biol 2011, 288:101-165

33. Montesano R, Vassalli JD, Baird A, Guillemin R, Orci L: Basic fibroblast growth factor induces angiogenesis in vitro. Proc Natl Acad Sci U S A 1986, 83:7297-7301

34. Zheng Y, Chen J, Craven M, Choi NW, Totorica S, Diaz-Santana A, Kermani P, Hempstead B, Fischbach-Teschl C, Lopez JA, Stroock AD: In vitro microvessels for the study of angiogenesis and thrombosis. Proc Natl Acad Sci U S A 2012, 109:9342-9347

35. Abrahamson DR, Robert B, Hyink DP, St John PL, Daniel TO: Origins and formation of microvasculature in the developing kidney. Kidney Int 1998, 67:S7-S11

36. Robert B, St John PL, Abrahamson DR: Direct visualization of renal vascular morphogenesis in Flk1 heterozygous mutant mice. Am J Physiol 1998, 275:F164-F172

37. Hellstrom M, Gerhardt H, Kalen M, Li X, Eriksson U, Wolburg H, Betsholtz C: Lack of pericytes leads to endothelial hyperplasia and abnormal vascular morphogenesis. J Cell Biol 2001, 153:543-553

38. Hellberg C, Ostman A, Heldin CH: PDGF and vessel maturation. Recent Results Cancer Res 2010, 180:103-114

39. Le Bras A, Vijayaraj P, Oettgen P: Molecular mechanisms of endothelial differentiation. Vasc Med 2010, 15:321-331

40. Armulik A, Genove G, Betsholtz C: Pericytes: developmental, physiological, and pathological perspectives, problems, and promises. Dev Cell 2011, 21:193-215

41. Byrne AM, Bouchier-Hayes DJ, Harmey JH: Angiogenic and cell survival functions of vascular endothelial growth factor (VEGF). J Cell Mol Med 2005, 9:777-794

42. Thommen R, Humar R, Misevic G, Pepper MS, Hahn AW, John M, Battegay EJ: PDGF-BB increases endothelial migration on cord movements during angiogenesis in vitro. J Cell Biochem 1997, 64: 403-413

43. Risau W, Drexler H, Mironov V, Smits A, Siegbahn A, Funa K, Heldin CH: Platelet-derived growth factor is angiogenic in vivo. Growth Factors 1992, 7:261-266

44. Lange S, Heger J, Euler G, Wartenberg M, Piper HM, Sauer H: Platelet-derived growth factor BB stimulates vasculogenesis of embryonic stem cell-derived endothelial cells by calcium-mediated generation of reactive oxygen species. Cardiovasc Res 2009, 81 $159-168$

45. Wagner B, Gorin Y: Src tyrosine kinase mediates platelet-derived growth factor BB-induced and redox-dependent migration in metanephric mesenchymal cells. Am J Physiol Renal Physiol 2014, 306: F85-F97

46. Alpers CE, Seifert RA, Hudkins KL, Johnson RJ, Bowen-Pope DF: Developmental patterns of PDGF B-chain, PDGF-receptor, and alpha-actin expression in human glomerulogenesis. Kidney Int 1992, 42:390-399

47. Hellstrom M, Kalen M, Lindahl P, Abramsson A, Betsholtz C: Role of PDGF-B and PDGFR-beta in recruitment of vascular smooth muscle cells and pericytes during embryonic blood vessel formation in the mouse. Development 1999, 126:3047-3055

48. Soriano P: Abnormal kidney development and hematological disorders in PDGF beta-receptor mutant mice. Genes Dev 1994, 8:1888-1896

49. Leveen P, Pekny M, Gebre-Medhin S, Swolin B, Larsson E, Betsholtz C: Mice deficient for PDGF B show renal, cardiovascular, and hematological abnormalities. Genes Dev 1994, 8:1875-1887

50. Voyta JC, Via DP, Butterfield CE, Zetter BR: Identification and isolation of endothelial cells based on their increased uptake of acetylated-low density lipoprotein. J Cell Biol 1984, 99:2034-2040

51. Yamamoto T, Sasaki S, Fushimi K, Ishibashi K, Yaoita E, Kawashaki K, Fujinaka H, Marumo F, Kihara I: Expression of AQP family in rat kidneys during development and maturation. Am J Physiol 1997, 272:F198-F204

52. Saadoun S, Papadopoulos MC, Hara-Chikuma M, Verkman AS: Impairment of angiogenesis and cell migration by targeted aquaporin1 gene disruption. Nature 2005, 434:786-792

53. Kim J, Kim WY, Han KH, Knepper MA, Nielsen S, Madsen KM: Developmental expression of aquaporin 1 in the rat renal vasculature. Am J Physiol 1999, 276:F498-F509

54. Millauer B, Wizigmann-Voos S, Schnuch H, Martinez R, Moller NP, Risau W, Ullrich A: High-affinity VEGF binding and developmental expression suggest Flk-1 as a major regulator of vasculogenesis and angiogenesis. Cell 1993, 72:835-846

55. Shalaby F, Ho J, Stanford WL, Fischer KD, Schuh AC, Schwartz L, Bernstein A, Rossant $\mathrm{J}$ : A requirement for Flk1 in primitive and definitive hematopoiesis and vasculogenesis. Cell 1997, 89:981-990

56. Yamaguchi TP, Dumont DJ, Conlon RA, Breitman ML, Rossant J: flk-1, an flt-related receptor tyrosine kinase is an early marker for endothelial cell precursors. Development 1993, 118:489-498

57. Tufro A, Norwood VF, Carey RM, Gomez RA: Vascular endothelial growth factor induces nephrogenesis and vasculogenesis. J Am Soc Nephrol 1999, 10:2125-2134

58. Simon M, Grone HJ, Johren O, Kullmer J, Plate KH, Risau W, Fuchs E: Expression of vascular endothelial growth factor and its receptors in human renal ontogenesis and in adult kidney. Am J Physiol 1995, 268:F240-F250

59. Takasato M, Er PX, Chiu HS, Maier B, Baillie GJ, Ferguson C, Parton RG, Wolvetang EJ, Roost MS, Chuva de Sousa Lopes SM, Little MH: Kidney organoids from human iPS cells contain multiple lineages and model human nephrogenesis. Nature 2015, 526: $564-568$

60. Patsch C, Challet-Meylan L, Thoma EC, Urich E, Heckel T, O’Sullivan JF, Grainger SJ, Kapp FG, Sun L, Christensen K, Xia Y, Florido MH, He W, Pan W, Prummer M, Warren CR, Jakob-Roetne R, Certa U, Jagasia R, Freskgard PO, Adatto I, Kling D, Huang P, Zon LI, Chaikof EL, Gerzten RE, Graf M, Iacone R, Cawan CA: Generation of vascular endothelial and smooth muscle cells from human pluripotent stem cells. Nat Cell Biol 2015, 17:994-1003

61. Mukherjee E, Maringer KV, Papke E, Bushnell DS, Schaefer CM, Kramann R, Ho J, Humphreys BD, Bates CM, Sims-Lucas S: Endothelial marker-expressing stromal cells are critical for kidney formation. Am J Physiol Renal Physiol 2017, 313:F611-F620

62. Renault M-A, Roncalli J, Tongers J, Thorne T, Klyachko E, Misener S, Volpert OV, Mehta S, Burg A, Luedemann C, Qin G, 
Kishore R, Losordo DW: Sonic hedgehog induces angiogenesis via Rho kinase-dependent signaling in endothelial cells. J Mol Cell Cardiol 2010, 49:490-498

63. Fabian SL, Penchev RR, St-Jacques B, Rao AN, Sipila P, West KA, McMahon AP, Humphreys BD: Hedgehog-Gli pathway activation during kidney fibrosis. Am J Pathol 2012, 180:1441-1453

64. Chen Q, Zhang H, Liu Y, Adams S, Eilken H, Stehling M, Corada M, Dejana E, Zhou B, Adams RH: Endothelial cells are progenitors of cardiac pericytes and vascular smooth muscle cells. Nat Commun 2016, 7:12422

65. Taguchi A, Kaku Y, Ohmori T, Sharmin S, Ogawa M, Sasaki H, Nishinakamura R: Redefining the in vivo origin of metanephric nephron progenitors enables generation of complex kidney structures from pluripotent stem cells. Cell Stem Cell 2014, 14: $53-67$
66. Halt KJ, Pärssinen HE, Junttila SM, Saarela U, Sims-Lucas S, Koivunen P, Myllyharju J, Quaggin S, Skovorodkin IN, Vainio SJ: CD146(+) cells are essential for kidney vasculature development. Kidney Int 2016, 90:311-324

67. Minuth WW, Denk L: Illustration of extensive extracellular matrix at the epithelial-mesenchymal interface within the renal stem/progenitor cell niche. BMC Clin Pathol 2012, 12:16

68. Iruela-Arispe ML, Davis GE: Cellular and molecular mechanisms of vascular lumen formation. Dev Cell 2009, 16:222-231

69. Huang C, Sheikh F, Hollander M, Cai C, Becker D, Chu PH, Evans S, Chen J: Embryonic atrial function is essential for mouse embryogenesis, cardiac morphogenesis and angiogenesis. Development 2003, 130:6111-6119

70. Gomez RA, Norwood VF, Tufro-McReddie A: Development of the kidney vasculature. Microsc Res Tech 1997, 39:254-260 